\title{
The BLOC-1 Subunit Pallidin Facilitates Activity- Dependent Synaptic Vesicle Recycling
}

\author{
(D)Xun Chen, ${ }^{1,2, *}$ Wenpei Ma, ${ }^{1, *}$ Shixing Zhang, ${ }^{1}$ Jeremy Paluch, ${ }^{1}$ Wanlin Guo, ${ }^{1}$ and ${ }^{-D i o n ~ K . ~ D i c k m a n ~}{ }^{1}$
}

\author{
DOI:http://dx.doi.org/10.1523/ENEURO.0335-16.2017
}

${ }^{1}$ Department of Biological Sciences, University of Southern California, Los Angeles, CA 90089, ${ }^{2}$ Neuroscience Graduate Program, University of Southern California, Los Angeles, CA 90089

\begin{abstract}
Membrane trafficking pathways must be exquisitely coordinated at synaptic terminals to maintain functionality, particularly during conditions of high activity. We have generated null mutations in the Drosophila homolog of pallidin, a central subunit of the biogenesis of lysosome-related organelles complex-1 (BLOC-1), to determine its role in synaptic development and physiology. We find that Pallidin localizes to presynaptic microtubules and cytoskeletal structures, and that the stability of Pallidin protein is highly dependent on the BLOC-1 components Dysbindin and Blos 1 . We demonstrate that the rapidly recycling vesicle pool is not sustained during high synaptic activity in pallidin mutants, leading to accelerated rundown and slowed recovery. Following intense activity, we observe a loss of early endosomes and a concomitant increase in tubular endosomal structures in synapses without Pallidin. Together, our data reveal that Pallidin subserves a key role in promoting efficient synaptic vesicle recycling and re-formation through early endosomes during sustained activity.
\end{abstract}

Key words: BLOC-1; Drosophila; endocytosis; endosome; neuromuscular junction; synaptic vesicle

\section{Significance Statement}

The speed and efficiency of synaptic vesicle recycling and re-formation are critical to maintain a functional synaptic vesicle pool during intense neuronal activity, yet the mechanisms that achieve this remain enigmatic. We show that the biogenesis of lysosome-related organelles complex-1 (BLOC-1) component Pallidin promotes rapid and efficient synaptic vesicle recycling through endosomal intermediates. Further, Pallidin is necessary for the integrity of Rab5-positive synaptic endosomes during sustained neurotransmission.

\section{Introduction}

Synaptic vesicle trafficking must be tightly coordinated to ensure rapid, efficient, and reliable replenishment fol-

Received November 7, 2016; accepted January 24, 2017; First published January 30, 2017.

The authors declare no competing financial interests.

Author contributions: X.C., W.M., S.Z., and D.K.D. designed research; X.C., W.M., S.Z., and J.P. performed research; W.G. contributed unpublished reagents/analytic tools; X.C., W.M., and S.Z. analyzed data; D.K.D. wrote the paper.

This research was supported by the National Institutes of Health $(\mathrm{NIH})$ National Institute of Mental Health Grant MH092351 and the NIH National Institute of Neurological Disorders and Stroke Grant NS019546 (to D.K.D.) as well as by funding from the Alfred P. Sloan, Ellison Medical, Mallinckrodt, Klingenstein-Simons, and Whitehall Foundations to D.K.D.

*X.C. and W.M. contributed equally to this work.

Acknowledgements: We thank Helmut Kramer (University of Texas, Southwestern, TX) for generously sharing the pallidin deletion stock; Marcos lowing exocytosis, particularly during intense levels of neuronal activity. To accomplish this, synapses are endowed with a variety of mechanisms to ensure fast and

Gonzalez-Gaitan (Geneva, Switzerland), Esteban Dell'Angelica (UCLA), the Bloomington Drosophila Stock Center, and the lowa Developmental Studies Hybridoma Bank for genetic and antibody reagents; and Victor Faundez (Emory University) for discussions and for communicating unpublished observations; and Liz Benecchi and the Harvard Medical School EM Facility for technical assistance with electron microscopy.

Correspondence should be addressed to Dion K. Dickman, Department of Neurobiology, 3641 Watt Way, HNB 309, Los Angeles, CA 90089. E-mail: dickman@usc.edu.

DOI:http://dx.doi.org/10.1523/ENEURO.0335-16.2017

Copyright (C) 2017 Chen et al.

This is an open-access article distributed under the terms of the Creative Commons Attribution 4.0 International, which permits unrestricted use, distribution and reproduction in any medium provided that the original work is properly attributed. 
robust synaptic vesicle recycling. It is clear that there are slow and fast forms of synaptic vesicle endocytosis (Sudhof, 2004; Smith et al., 2008; Kononenko and Haucke, 2015), and that dynamin is necessary for vesicular fission (Ferguson and De Camilli, 2012; Rizzoli, 2014). There are at least three fundamental trafficking pathways for synaptic vesicles at the synapse. These include clathrinmediated endocytosis and direct re-formation of synaptic vesicles to the fusion competent pool (Murthy and De Camilli, 2003; McMahon and Boucrot, 2011), trafficking of synaptic vesicles through endosomal intermediates (de Hoop et al., 1994; Salem et al., 1998; Wucherpfennig et al., 2003; Voglmaier et al., 2006; Brown et al., 2009; Hoopmann et al., 2010; Uytterhoeven et al., 2011; Kononenko and Haucke, 2015), and bulk endocytosis pathways (Murthy and De Camilli, 2003; Clayton and Cousin, 2009a; Wu et al., 2014; Soykan et al., 2016). Further, following re-formation of functional synaptic vesicles through these routes, these vesicles must be organized into pools of varying locations, releasable states, and biochemical interactions that ultimately maintain neurotransmission and determine synaptic strength (Rizzoli, 2014). Although several of the key molecules involved in the essential steps of membrane trafficking have been identified, much less is known about how synaptic vesicle recycling is dynamically modulated to meet the changing demands of synapses during sustained neurotransmission. More specifically, how the demands of synapses during intense stimulation are transduced to enable adaptive modulations in the speed and destinations of synaptic vesicle transport remains enigmatic.

Endosomes are key nodes of signaling and trafficking during synaptic vesicle recycling. Although Rab5 and other factors are known be involved in synaptic endosomal function (Wucherpfennig et al., 2003; Uytterhoeven et al., 2011; Kononenko and Haucke, 2015), our understanding of synaptic vesicle trafficking through endosomes remains incomplete. The biogenesis of the lysosome-related organelles complex-1 (BLOC-1) complex has been implicated in endosomal sorting in a variety of tissues, but its role at synapses is not established. The BLOC-1 is composed of eight subunits, Blos1, Blos2, Blos3, Snapin, Dysbindin, Pallidin, Muted, and Cappuccino (Falcón-Pérez et al., 2002; Ciciotte et al., 2003; Li et al., 2003; Starcevic and Dell'Angelica, 2004; Lee et al., 2012). Mutations in human pallidin and other BLOC-1 components are associated with Hermansky-Pudlak syndrome, a disease in which trafficking and biogenesis of platelets, lysosomes, and other endosomal organelles are impaired (Wei, 2006). In addition, mutations in the BLOC-1 components dysbindin, muted, and blos3 have been associated with schizophrenia (Straub et al., 2002; Morris et al., 2008; Ryder and Faundez, 2009; Ghiani and Dell'Angelica, 2011). The central component of this complex is Pallidin, which biochemically interacts with Dysbindin, Blos1, and Cappuccino (Starcevic and Dell'Angelica, 2004; Lee et al., 2012). However, the role of Pallidin and BLOC-1 in the nervous system in general, and at synapses in particular, is not understood.

The fruit fly Drosophila melanogaster is an attractive model system to elucidate the role of pallidin at synapses.
The fly genome encodes single orthologs of each vertebrate BLOC-1 subunit, including pallidin (Cheli et al., 2010; Mullin et al., 2015), and there is evidence for similar interactions between subunits (Cheli et al., 2010). Drosophila blos 1 has been implicated in pigmentation trafficking in photoreceptors (Cheli et al., 2010), while dysbindin and snapin were found to be necessary for presynaptic homeostatic plasticity (Dickman and Davis, 2009; Dickman et al., 2012), an adaptive form of synaptic plasticity that leads to an increase in presynaptic release in response to perturbation of postsynaptic neurotransmitter receptors, maintaining stable levels of synaptic strength (Frank, 2014; Davis and Müller, 2015). Finally, in addition to the sophisticated genetic approaches available in Drosophila, the fly neuromuscular junction (NMJ) permits powerful electrophysiological, imaging, and cell biological tools with the potential to reveal the functions of pallidin and other BLOC-1 subunits in synaptic structure and function.

To gain insight into the role of BLOC-1 at synapses, we have generated mutations in the Drosophila homolog of pallidin. Our characterization of synaptic development and physiology in these mutants has revealed that Pallidin is localized to cytoskeletal structures at synaptic terminals but is surprisingly dispensable for synaptic growth, structure, baseline function, and homeostatic plasticity. However, pallidin is necessary to replenish depleted synaptic vesicles during high levels of activity by promoting the rapid trafficking and re-formation of vesicles through endosomal intermediates. Thus, Pallidin has an important function in maintaining and replenishing the activity-dependent synaptic vesicle pool.

\section{Materials and Methods}

\section{Drosophila genetics and molecular biology}

Drosophila stocks were raised at $25^{\circ} \mathrm{C}$ on standard molasses media containing $12-\mathrm{g}$ inactive yeast, $60-\mathrm{g}$ cornmeal, 6-g agar, $74-\mathrm{ml}$ molasses, $5.5-\mathrm{ml}$ propionic acid, and $11-\mathrm{ml}$ tegosept $(10 \% \mathrm{w} / \mathrm{v})$ per liter. It was communicated to us that raising pldn mutants in an alternative food source, containing $36-\mathrm{g}$ inactive yeast, $89-\mathrm{g}$ cornmeal, 6.6-g agar, 89-ml molasses, 6.6-ml propionic acid, and $17.8-\mathrm{ml}$ tegosept $(10 \% \mathrm{w} / \mathrm{v})$ per liter results in changes in synaptic growth in pldn and other BLOC-1 mutants that were not observed using the recipe used in this study (V. Faundez, personal communication). The reasons for this distinction are under active investigation by Dr. Faundez.

The precise deletion of the pallidin locus was generated using flippase (FLP) recombinase-mediated recombination between pairs of transposon-based FRT sites, as described in the DrosDel Collection (Parks et al., 2004). Specifically, two transposons flanking the pallidin locus, $p B a c^{f 05716}$ and $p B a c^{f 05753}$ (Thibault et al., 2004), were obtained from the Bloomington Drosophila Stock Center. Each contained flippase recombination target (FRT) sites in the correct orientation to permit a precise deletion. Following FLP-mediated recombination and excision of the remaining hybrid transposon, we confirmed the deletion by PCR using the following primers: 
forward primer 5'-GTCATTGGGTGCAAAGTGCTC; reverse primer 5'-CTCCCGAGCTGCATGTTGAATC. This revealed that bases $11,689,565$ to $11,691,527$ on chromosome $3 \mathrm{~L}$ were deleted. We named this mutant allele pld $n^{\Delta 1}$. The transcript of the gene located $5^{\prime}$ to pallidin is not perturbed, while an estimated 591 bases of the 3'UTR of sugb, the gene located 3' to the pldn locus, is deleted in pld $n^{\Delta 1}$. This region overlaps with the predicted pallidin 3'UTR, making it difficult to conclude whether the neighboring gene is impacted. The $w^{1118}$ strain was used as the wild-type control unless otherwise noted, as this was the genetic background in which all genotypes were bred. UASGFP-myc-2xFYVE was obtained from Marcos GonzalezGaitan (Wucherpfennig et al., 2003), and blos $1^{\text {ex2 }}$ (Cheli et al., 2010) was a gift from Esteban Dell'Angelica (UCLA). Df(3L)BSC675 (pldn deficiency) and dysbindin ${ }^{\mathrm{e} 1028}$ (refered to as $d y s b^{1}$ ) was obtained from Bloomington Drosophila Stock Center (Bloomington, IN), as were all others unless otherwise noted. Standard second and third chromosome balancers and genetic strategies were used for all crosses and for maintaining mutant lines. For all experiments, animals of either sex were used unless otherwise specified.

We obtained cDNA of the entire pallidin open reading frame from the Berkeley Drosophila Genome Project (IP05492). We cloned the pallidin cDNA into the pACU2 vector (Han et al., 2011) using standard cloning methods (5' EcoR1 restriction enzyme; 3' Xba1 restriction enzyme) to generate UAS-pallidin. For generation of UAS-pallidin$3 x f l a g$ we inserted synthesized 3xflag coding sequence: GCATGGATTACAAGGATCACGACGGCGATTACAAGGA TCACGACATCGATTACAAGGATGACGATGATAAGTAA and cloned the sequence into the pACU2 vector using standard cloning methods (5' Nde1 restriction enzyme; 3 ' Spe1 restriction enzyme), we then cloned the pallidin cDNA into this pACU2 vector that contains the 3xflag sequence using standard cloning methods (5' EcoR1 restriction enzyme; 3' Xba1 restriction enzyme). These constructs were sequenced and sent to BestGene for recombination-mediated insertion into the VK18 (Venken et al., 2006) recombination site on the second chromosome.

\section{Immunochemistry and immunoblot analysis}

Wandering third-instar larvae were dissected with pins on a Sylgard dish, fixed in Bouin's fixative (Sigma, $\mathrm{HT} 10132-1 \mathrm{~L}$ ) or $4 \%$ paraformaldehyde in PBS (Sigma, F8775), and immunostained with primary antibodies diluted in PBST (PBS supplemented with $0.05 \%$ Triton $X-100$, Sigma, X100) at $4^{\circ} \mathrm{C}$ overnight or room temperature for $30 \mathrm{~min}$, followed by 3 times washing with PBST and secondary antibody incubation at room temperature for $2 \mathrm{~h}$, samples were then washed three times with PBST and mounted on a glass slide for imaging. To generate the Pallidin antibody used in this study, we synthesized a peptide consisting of amino acids GRQNKTYIDLSKEKYK of the Pallidin amino acid sequence (amino acids 80-95). This peptide was conjugated to KLH and injected into rabbits to obtain immunosera that was subsequenctly affinity purified (Yenzym). The following primary antibodies were used at the indicated dilutions: mouse anti-BRP nc82 1:100 (Developmental Studies Hybridoma Bank; DSHB, RRID:AB_2314867), rabbit anti-DLG 1:10,000 (Koh et al., 1999), mouse anti-SYN 1:20 (3C11; DSHB, RRID: AB_2313867), guinea pig anti-vGlut (1:200), goat antiHRP 1:200 (directly conjugated to Alexa Fluor 647; Jackson ImmunoResearch), mouse anti-Futsch 22C10 1:50 (Developmental Studies Hybridoma Bank; DSHB, RRID: $A B$ 528403), and rabbit anti-PLDN 1:200. Alexa Fluor 488- and Cy3-conjugated donkey secondary antibodies (Jackson ImmunoResearch) were used at 1:400. Images were acquired with a Nikon A1R Resonant Scanning Confocal microscope equipped with NIS Elements software and a 100 $\times$ APO 1.4NA oil immersion objective. Settings were optimized for detection without saturation of the signal. Z-stacks were obtained using identical settings within each experiment and maximal intensity projection of each Z-stack were used for analysis. Bouton numbers were quantified directly from preparations stained for Synapsin under a confocal microscope on muscle 6 and 7 of segment A3. BRP number and density and Pldn intensity were quantified using NIKON NIS-Elements Advanced Research software, intensity values were measured as mean intensity. BRP number, density, and HRP area were quantified from images of muscle 4 segment A3. Pldn intensity was quantified from images of muscle 6 and 7 of segment $A 2$.

For GFP-2XFYVE live imaging, animals were dissected in $0.4 \mathrm{mM} \mathrm{Ca}^{2+} \mathrm{HL}-3$ and incubated in modified $\mathrm{HL}-3$ with $2 \mathrm{mM} \mathrm{Ca}^{2+}, 90 \mathrm{mM} \mathrm{K}^{+}$(high $\mathrm{K}^{+}$) HL-3 for 5 min for high $\mathrm{K}^{+}$ stimulation. GFP-2XFYVE and Cy3-HRP (Jackson ImmunoResearch, 1:400) were imaged using a Zeiss LSM700 confocal microscope equipped with Zen software using a $63 \times 1.0$ NA water immersion objective. Analysis of GFP2XFYVE puncta, including the density (number of GFP2XFYVE puncta/HRP area), size, and intensity, was performed using ImageJ (NIH). For analysis of size and intensity, the number of puncta after high $\mathrm{K}^{+}$was normalized to each genotype's puncta number at rest.

For immunoblot analysis, 50 adult heads were collected and homogenized in 100- $\mu$ l lysis buffer (10 mM HEPES, $\mathrm{pH} 7.4 ; 150 \mathrm{mM} \mathrm{NaCl}$; protease inhibitors (Roche); and $1 \%$ Triton $X-100$ ). A total of $10 \mu \mathrm{l}$ of protein lysate was separated by SDS-PAGE and transferred to PVDF membranes. Western blot analysis was performed according to manufacturer's protocols. SuperSignal West Femto Maximum sensitivity substrate (Thermo Scientific) were used for $x$-ray film-based band visualization. The film were scanned and band intensities were quantified with ImageJ (NIH). The following antibodies were used: rabbit anti-PLDN 1:1000, mouse anti- $\alpha$-tubulin 1:2000 (T6199, Sigma-Aldrich).

\section{Electrophysiology}

Electrophysiology was performed using a Zeiss Axioscope AX10 fixed stage microscope equipped with a $40 \times$ 0.8 NA water-dipping objective. Third-instar larvae were dissected and bathed in a modified $\mathrm{HL}-3$ saline: $70 \mathrm{mM}$ $\mathrm{NaCl} ; 5 \mathrm{mM} \mathrm{KCl} ; 10 \mathrm{mM} \mathrm{MgCl}_{2} ; 10 \mathrm{mM} \mathrm{NaHCO}_{3} ; 115 \mathrm{mM}$ sucrose; $5 \mathrm{mM}$ trehelose; $5 \mathrm{mM}$ HEPES, $\mathrm{pH}$ 7.2; and a calcium concentration of $0.4 \mathrm{mM}$ unless otherwise specified. Sharp electrode current-clamp recordings were per- 
formed on muscles 6 and 7 in abdominal segments $A 2$ or A3. Severed ventral nerves were stimulated using a $5 \mathrm{~V}$ command pulse at $3 \mathrm{~ms}$ stimulus duration through pClamp software to an Isoflex stimulation unit (A.M.P.I.). Data were acquired using an Axoclamp 900A amplifier, digitized using a Digidata 1440A, and controlled using pClamp 10.5 software (Molecular Devices). Electrophysiological sweeps were sampled at a rate of $10 \mathrm{kHz}$ and filtered at $400 \mathrm{~Hz}$. Data were analyzed using MiniAnalysis (Synaptosoft), SigmaPlot (Systat Software), GraphPad Prism, Microsoft Excel, and SPSS 13.0. Quantal content was calculated for each individual recording by calculating the average EPSP, average miniature EPSP (mEPSP), and corrected for nonlinear summation for the calciumcooperativity analysis, using equation $\mathrm{QC}_{\text {corrected }}=(\mathrm{EPSP} /$

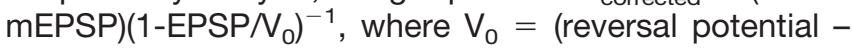
resting potential) (Martin, 1955). Corrected and noncorrected quantal content values were compared in all experiments, and in no case did quantal content values change any conclusion. A recording electrode (15- to 30- $\mathrm{M} \Omega$ resistance) filled with $3 \mathrm{M} \mathrm{KCl}$ was used, and data were only analyzed from cells with a resting potential more hyperpolarized than $-60 \mathrm{mV}$, input resistance of at least $5 \mathrm{M} \Omega$, and resting potentials that did not deviate by more than $5 \%$ for the duration of the recording. For acute pharmacological homeostatic challenge, semi-intact preparations, with the CNS, and gut left intact, were perfused with Philanthatoxin-433 (20 $\mu \mathrm{M}$ in HL3, Sigma) for 10 min followed by full dissection and electrophysiological recording as described previously (Frank et al., 2006). For failure analysis, recordings were performed in $0.1 \mathrm{mM} \mathrm{Ca}^{2+}$ saline, and percent failure of EPSP was calculated from 40 stimulation trials in each recording. To determine asynchronous release rates, mEPSP frequency was calculated for the 2-s period immediately following EPSP stimulation of 30 EPSP trials during each recording.

Two electrode voltage clamp recordings were used to determine the readily releasable pool (RRP) size. Recordings were made from cells with input resistances $\geq 5 \mathrm{M} \Omega$ and membrane potentials between -55 and $-70 \mathrm{mV}$ in modified HL-3 saline containing $3 \mathrm{mM}$ extracellular calcium. Intracellular electrodes with resistances of 10-30 $\mathrm{M} \Omega$ filled with $3 \mathrm{M} \mathrm{KCl}$ were used. The holding potential was $-70 \mathrm{mV}$. EPSC amplitudes during a stimulus train $(60 \mathrm{~Hz}$, 60 stimuli) were calculated as the difference between the peak and baseline before stimulus onset of a given EPSC. The number of release-ready vesicles was obtained by back-extrapolating a line fit to the linear phase of the cumulative EPSC plot (the last 30 stimuli) to time 0 and dividing the cumulative EPSC amplitude at time 0 by the mean mEPSC amplitude recorded in the same cell, as described previously (Muller et al., 2012).

\section{Electron microscopy}

EM analysis was performed as described previously (Kaufmann et al., 2002). Wandering third-instar larvae were dissected in $\mathrm{Ca}^{2+}$-free $\mathrm{HL}-3$ saline (rest) or $2 \mathrm{mM}$ $\mathrm{Ca}^{2+}, 90 \mathrm{mM} \mathrm{K}^{+}$(high $\mathrm{K}^{+}$) modified $\mathrm{HL}-3$ saline, then fixed in $2.5 \%$ paraformaldehyde/5.0\% glutaraldehyde/0.06\% picric acid/0.1 M cacodylate buffer for $\sim 18 \mathrm{~h}$ at room temperature. Fillets were rinsed three times for twenty minutes in $0.1 \mathrm{M}$ cacodylate buffer. The larval pelts were then placed in 1\% osmium tetroxide/potassium ferrocyanide mix buffer $\left(1 \% \mathrm{OsO}_{4}, 1.5 \% \mathrm{~K}_{4}\left[\mathrm{Fe}(\mathrm{CN})_{6}\right]\right.$ in water) for 1 $\mathrm{h}$ at room temperature. After rinsing and dehydration in an ethanol series, samples were cleared in propylene oxide and infiltration with half propylene oxide and half TAAB resin overnight at $4^{\circ} \mathrm{C}$. The following day, samples were embedded in fresh TAAB resin. EM sections were obtained on a JEOL 1200EX microscope at the EM Facility of Harvard Medical School. The 6/7 muscle region was located by taking $0.5-\mu \mathrm{m}$ sections and the bouton regions were located by taking $90-\mathrm{nm}$ sections until boutons were identified. The blocks were then trimmed and serial sectioned at a 60-nm thickness for approximately $240 \mathrm{sec}-$ tions. The sections were mounted on Formvar-coated single slot grids and viewed at a 25,000 $\times$ magnification. Measurements were taken to scale with $10 \times$ lupe $/ \mathrm{mm}$. Images were analyzed blind to genotype using ImageJ (NIH) and Adobe Photoshop (Adobe Systems) software. The 3D reconstruction model was generated using IMOD software (Kremer et al., 1996).

\section{Statistical analyses}

Statistical analyses were performed using SPSS 13.0 software (IBM). Student's $t$ test was used to compare two groups. The one-way ANOVA plus post hoc LSD (with equal variances) or Tamhane's T2 (with unequal variances) tests were used to compare three or more groups. Statistical significance was defined as $p<0.05$ levels. All data are presented as group means \pm SEM.

\section{Results}

\section{Generation and analysis of mutations in the \\ Drosophila homolog of pallidin}

Pallidin is a core component of the BLOC-1 complex ( $\mathrm{Li}$ et al., 2003; Starcevic and Dell'Angelica, 2004; Lee et al., 2012) but has not been studied in Drosophila. We identified independent transposon insertions flanking the Drosophila pallidin locus (CG14133; hereafter abbreviated pldn). These piggyBac transposons fortuitously carried FRT sequences in the same orientation, enabling FLPmediated recombination and excision of the intervening sequence (Parks et al., 2004; Ryder et al., 2007). Following recombination and precise excision of the remaining hybrid transposon, the entire open reading frame of the pldn locus was removed (Fig. 1A; this allele referred to as pld $\left.n^{\Delta 1}\right)$, and the genetic lesion was confirmed by PCR (Fig. $1 B$ ). pldn $n^{\Delta 1}$ mutants were viable and fertile and could be maintained as healthy homozygous stocks.

Immunoblot analysis revealed that PIdn is expressed as a single band at $19 \mathrm{kDa}$ (Fig. 1C), consistent with the predicted molecular weight of the lone isoform in the Drosophila genome. This $19-\mathrm{kDa}$ band was absent in heads of $p / d n^{\Delta 1}$ mutants, confirming the specificity of the PIdn antibody, and overexpression of a UAS-pldn-3xflag transgene revealed increased Pldn protein running at a slightly larger size, as expected with the 3xflag tag (Fig. 1C). Pldn was expressed in all stages examined (embryos through adults) and was present in larval and adult brain 

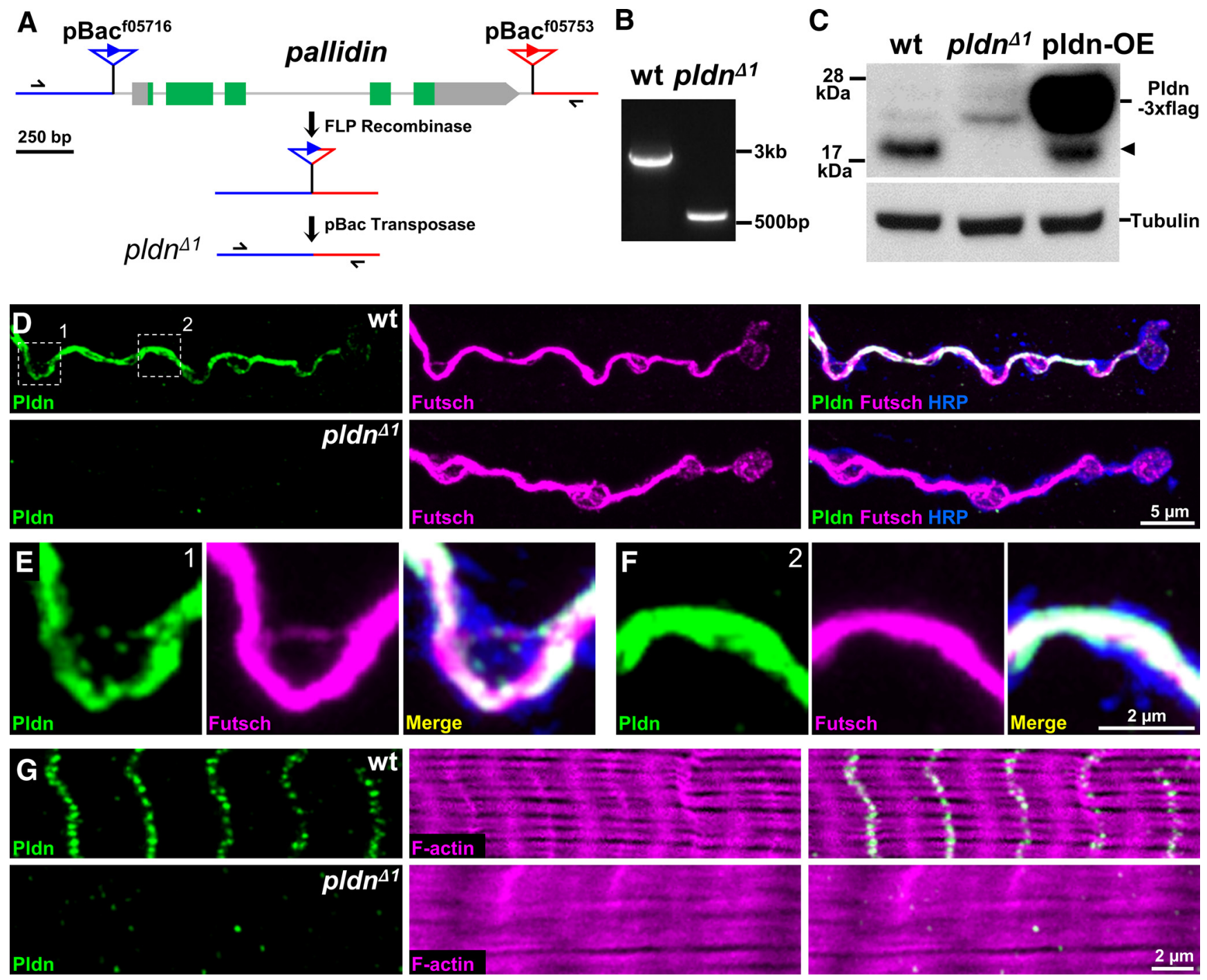

Figure 1. Generation of pallidin null mutations and synaptic localization of Pldn protein. $\boldsymbol{A}$, Schematic of the workflow utilized to generate the excision of the pallidin locus. Black arrows indicate primers used for PCR confirmation of the excision. B, PCR confirmation of the deletion of the pldn locus. $\boldsymbol{C}$, Immunoblot analysis of adult heads lysates from wild type $\left(w^{1118}\right), p^{\prime d} n^{\Delta 1}$ mutants $\left(w^{1118} ; p / d n^{\Delta 1}\right)$, and neuronal pldn overexpression (pldn-OE; c155-Gal4/Y;UAS-p/dn-3xflag/+), which reveals a band running at 19 $\mathrm{kDa}$, the predicted molecular weight of Drosophila PIdn. This band (indicated by arrowhead) is absent in pldn ${ }^{\Delta 1}$ and increased in pldn-OE. Anti- $\alpha$-tubulin immunoblot was used as loading control. $\boldsymbol{D}$, Representative images of third-instar larval NMJs from wild-type and pldn ${ }^{\Delta 1}$ mutants immunostained for Pldn (green) and the neuronal microtubule marker Futsch (magenta). The neuronal membrane is immunolabeled with anti-HRP (blue). $\boldsymbol{E}$, Magnified images of area 1 and area $2(\boldsymbol{F})$ marked in $\boldsymbol{D}$, exhibiting a high degree of colocalization between Pldn and Futsch. G, Representative images of third-instar larval muscle immunostained for Pldn (green) and F-actin (phalloidin; magenta), showing Pldn localization to the muscle $Z$ band.

and body extracts (data not shown), consistent with Drosophila Pldn, like the vertebrate homolog, being broadly expressed. Together, this demonstrates that pldn is broadly expressed and that $p / d n^{\Delta 1}$ is a null mutation.

Pallidin localizes to presynaptic microtubules and is not required for synaptic growth or structure

In vertebrates, Pldn is associated with the AP-3 complex, F-actin, and Syntaxin 13 (Huang et al., 1999; Parast and Otey, 2000; Bang et al., 2001; Falcón-Pérez et al., 2002; Di Pietro et al., 2006; Delevoye et al., 2016), suggesting that Pldn may interact with both the cytoskeleton and endosomal structures, but whether this association holds at synapses is not known. We therefore examined the synaptic expression and localization of Pldn at the Drosophila NMJ. PIdn immunostaining revealed a specific signal in both presynaptic terminals of motor neurons as well as in postsynaptic muscles. In presynaptic terminals, Pldn immunostaining appeared to label neuronal microtubule structures, significantly overlapping with Futsch, a marker for neuronal microtubules (Hummel et al., 2000) (Fig. 1D-F). This signal was absent in pld $n^{\Delta 1}$ mutant synapses (Fig. 1D), confirming the specificity of this antibody and that $p / d n^{\Delta 1}$ is a null mutation. In the postsynaptic muscle, Pldn appeared to localize to Z-disc structures (Fig. $1 G)$, consistent with observations of PIdn association in 
vertebrate striated muscle (Bang et al., 2001; Parast and Otey, 2000). These Z-discs are cytoskeletal anchors for muscle filaments as well as signal transduction centers (Clark et al., 2002; Collin et al., 2012; Granger et al., 2014; Delevoye et al., 2016). We also noted that the normally organized F-actin bundles in the muscle, labeled with phalloidin, appeared disorganized in pldn mutants (Fig. $1 G)$. Thus, Pldn is present in both pre- and postsynaptic compartments at the Drosophila NMJ, where it is associated with cytoskeletal structures.

Recent studies have suggested that pldn and other components of the BLOC-1 complex have roles in synaptic development (Ghiani et al., 2010; Wu et al., 2011; Zhou et al., 2012; Mullin et al., 2015). We therefore examined synaptic growth and structure in $p / d n^{\Delta 1}$ mutants as well as in pld $n^{\Delta 1}$ in trans with a deficiency $\left(p / d n^{\Delta 1 / D}\right)$. We immunolabeled the NMJ with antibodies specific to the presynaptic neuronal membrane (HRP), the postsynaptic density (discs large; DLG), presynaptic active zones (Bruchpilot; BRP), synaptic vesicles (Synapsin; SYN; vesicular glutamate transporter; vGlut), and postsynaptic glutamate receptors (GluRIII and GluRIIA). No major differences in synapse morphology or structure were observed in pld $n^{\Delta 1}$ mutants or pld $n^{\Delta 1 / D f}$, nor did we note any changes in axon guidance or targeting of motor neurons to their proper target muscle (Fig. $2 A, B$ and data not shown). To measure synaptic growth and structure, we quantified membrane surface area (HRP area), the number of synaptic boutons, and the density and numbers of active zones (Fig. 2C-F). We found no significant difference in any of these values in pld $n^{\Delta 1}$ mutants compared with wild type, nor did we observe any changes in the organization of postsynaptic glutamate receptors (Fig. $2 A, B$ and data not shown). Thus, we conclude that pldn is not required for proper synaptic morphogenesis, growth, or architecture.

\section{Pallidin stability depends on the BLOC-1 components Dysbindin and Blos1}

Biochemical studies of the BLOC-1 complex have demonstrated that the stability of some BLOC-1 components depend on the presence of other components, and Pldn protein levels are reduced in dysbindin, cappuccino, muted, and blos3 mutants (Falcón-Pérez et al., 2002; Ciciotte et al., 2003; Li et al., 2003; Starcevic and Dell'Angelica, 2004). We therefore examined Pldn expression in the two other genetic mutations in BLOC-1 subunits that exist in Drosophila, dysbindin (dysb) (Dickman and Davis, 2009) and blos1 (Cheli et al., 2010). We observed a reduction in Pldn immunolabeling at NMJ synapses in both mutants, with an almost complete loss of Pldn in $d y s b^{1}$ mutants $(92.4 \%$ reduction), and a more moderate reduction in blos $1^{\text {ex2 }}$ mutants $(31.5 \%$ reduction; Fig. $3 A, B)$. Further, we examined Pldn protein stability by immunoblot of lysates from $d y s b^{1}$ and blos $1^{\text {ex2 }}$ mutant heads. Similarly, we observed a drastic loss of Pldn in $d y s b^{1}$ mutants ( $71.6 \%$ reduction), with an even larger reduction in blos $1^{\text {ex }}$ mutants $(96.2 \%$ reduction; Fig. 3C,D). Given the large reduction of Pldn in $d y s b$ mutants, we asked whether overexpression of pldn in dysb mutants could overcome the dependency of PIdn stability on endogenous Dysb. Surprisingly, we observed no significant difference in Pldn immunostaining when pldn was neuronally overexpressed in dysb mutants (Fig. $3 A, B$ ). Finally, we asked whether the dependence of Pldn stability on dysb was reciprocal. To address this question, we overexpressed a UAS-Venus-Dysbindin transgene in neurons in a wild-type and pldn mutant background and immunostained NMJs for Venus-Dysbindin. We found no reduction in Venus-Dysbindin levels in pldn mutants compared with wild type (Fig. 3E). In fact, we observed a significant increase in Venus-Dysbindin expression in pldn mutants (1.91-fold increase; $p<0.001$; Student's $t$ test), suggesting that Pldn may actually limit the stability of Dysbindin. Thus, Dysbindin and Pallidin protein stability are not reciprocally dependent on each other.

Together, these data demonstrate three important points about the dependency of Pldn stability on other BLOC-1 subunits. First, although PIdn stability is dependent on other BLOC-1 components, as observed biochemically (Falcón-Pérez et al., 2002; Ciciotte et al., 2003; Li et al., 2003; Gwynn et al., 2004), this dependence is not uniform, with Pldn at synaptic terminals appearing to be more sensitive to levels of $d y s b$ than to blos1. Second, Pldn levels at synaptic terminals, as determined by immunostaining, did not quantitatively correspond to the reduction in levels observed in whole head lysates by immunoblot, suggesting there may be differential dependency for Pldn stability in neuronal compartments and/or cell types. Third, at least in the case of Dysb stability, pldn does not exert the same control of stability on Dysb compared with the dependency of Pldn on dysb. Rather, Dysb levels are not reduced when overexpressed in pldn mutants, and appear to actually increase at synaptic terminals.

\section{Pallidin is dispensable for baseline neurotransmission and presynaptic homeostatic potentiation}

Synaptic physiology has not been examined in pallidin mutants in any system, although changes in basal synaptic transmission have been observed in other BLOC-1 mutants (Numakawa et al., 2004; Chen et al., 2008; Dickman and Davis, 2009; Pan et al., 2009; Tang et al., 2009; Cheli et al., 2010). We therefore characterized synaptic physiology at the NMJ in $p / d n^{\Delta 1}$ mutants and $p / d n^{\Delta 1 / D f}$, comparing values of miniature EPSP (mEPSP) frequency, mEPSP amplitude, evoked EPSP amplitude, and quantal content across a range of extracellular calcium conditions. We observed no major differences in mEPSP frequency, amplitude, or EPSP amplitudes in standard saline (0.4 mM extracellular $\mathrm{Ca}^{2+}$ ) in pldn mutants compared with controls (Fig. 4A,C-E). In addition, there was no change in the apparent calcium cooperativity of synaptic transmission, with $p / d n^{\Delta 1}$ mutants releasing similar quantal content across a range of extracellular calcium concentrations compared with wild type (Fig. 4B). We went on to test the state of presynaptic function in further detail, examining asynchronous release, presynaptic release probability (failure analysis), and the size of the readily releasable synaptic vesicle pool. We observed no signifi- 


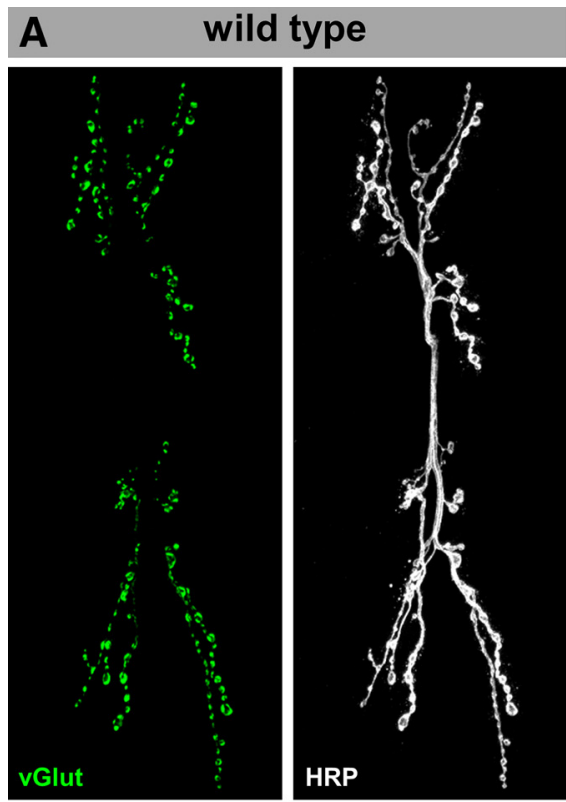

\section{B pldnt1}
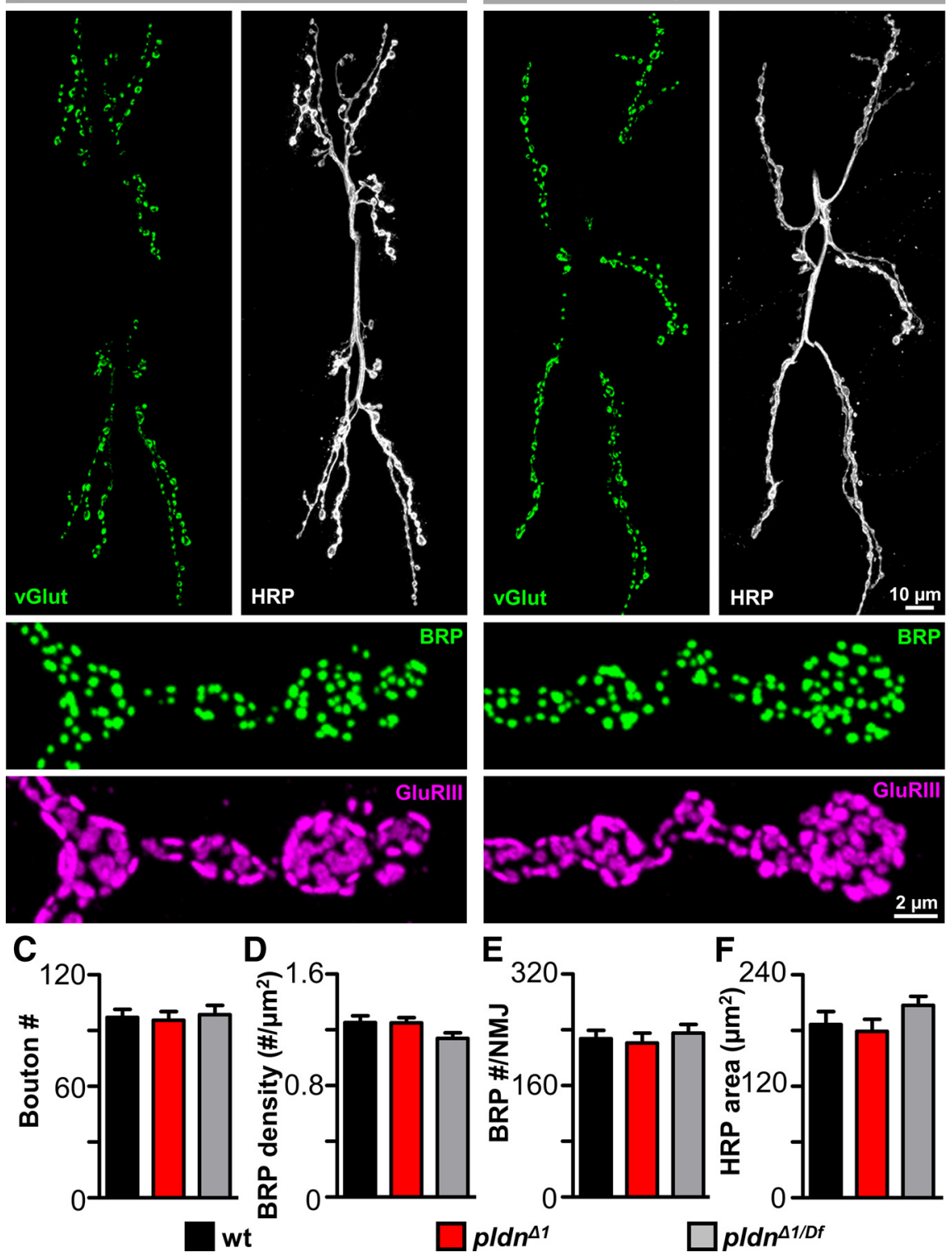

Figure 2. Synaptic growth and structure is unperturbed in pallidin mutants. Representative images of muscle 6/7 NMJs from wild type $\left(w^{1118}\right)(\boldsymbol{A})$ and pld $n^{\Delta 1}$ mutants $(\boldsymbol{B})$ immunostained with anti-vGlut (synaptic vesicle marker; green), anti-HRP (white). Below, wild-type and pld $n^{\Delta 1}$ NMJs on muscle 4 immunostained with anti-BRP (active zone marker; green) and GluRIII (postsynaptic glutamate receptor marker; magenta). No significant differences are observed in bouton number $(\boldsymbol{C})$, BRP density $(\boldsymbol{D})$, BRP number/NMJ $(\boldsymbol{E})$, or HRP area $(\boldsymbol{F})$ in wild-type $(n=12)$, $p / d n^{\Delta 1}(n=12)$, and $p / d n^{\Delta 1 / D f}\left(w^{1118} ; p / d n^{\Delta 1} / D f(3 L) B S C 675 ; n=10\right) . p>0.05$; one-way ANOVA for all parameters.

cant difference in asynchronous release (Fig. 4F), failure analysis (Fig. 4G), synaptic transmission at elevated extracellular calcium using two electrode voltage clamp (2 mM; Fig. $4 H$ ), or the estimated size of the readily releasable vesicle pool (Fig. 4/). Thus, surprisingly, pldn null mutants have no major defects in synaptic growth, structure, or baseline function, whereas changes in these processes have been reported in mutations in other BLOC-1 subunits.

The Drosophila NMJ has been established as a powerful model synapse to characterize presynaptic homeostatic plasticity (Frank et al., 2013; Davis and Müller, 2015). Using an acute pharmacological assay in which subblocking concentrations of the postsynaptic glutamate receptor antagonist philanthotoxin (PhTx) is applied to the dissected larval NMJ, mEPSP amplitude is reduced due to the irreversible binding of the toxin (Frank et al., 2006). However, EPSP amplitude is restored to baseline levels due to a rapid, homeostatic increase in presynaptic release (quantal content). The BLOC-1 components dysbindin and snapin have previously been shown to be required for this homeostatic increase in presynaptic release, where quantal content remains unchanged in these mutants after application of $\mathrm{PhTx}$, leading to a reduced EPSP amplitude (Dickman and Davis, 2009). Given that 


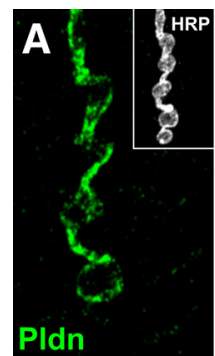

wt

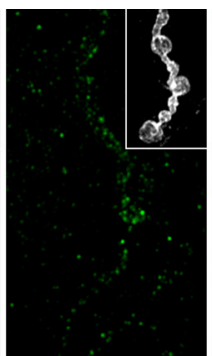

$p / d n^{\Delta 1}$

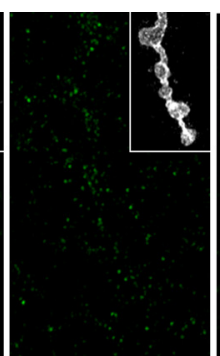

$d y s b^{1}$

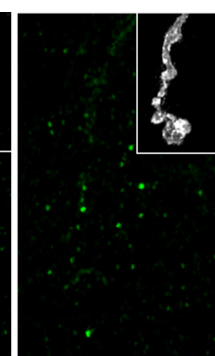

dysb +pldn-OE

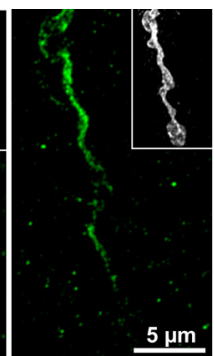

blos1ex2

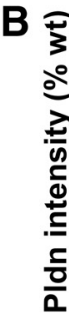

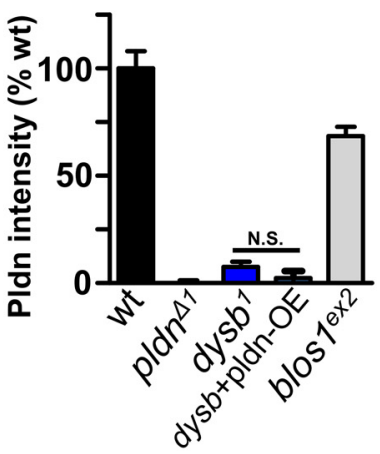

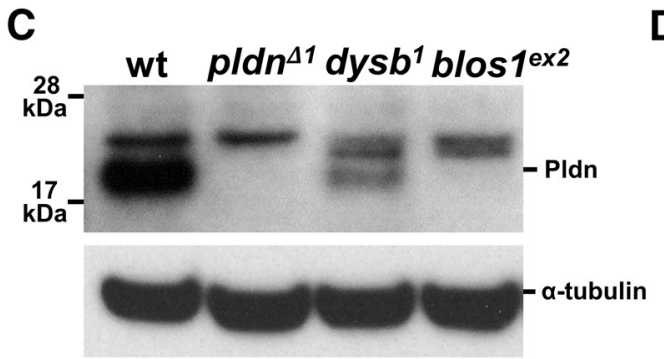
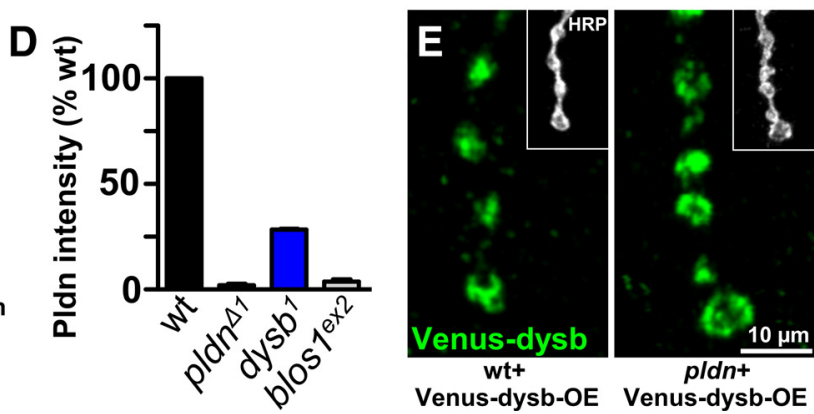

Figure 3. Pallidin stability is dependent on dysbindin and blos1. $\boldsymbol{A}$, Representative images of Pldn immunostaining (green) in NMJs of wild type, $p / d n^{\Delta 1}, d y s b^{1}\left(w^{1118} ; d y s b^{1}\right)$, dysb+pldn-OE $\left(w^{1118} ;\right.$ OK6/UAS-pldn-3xflag;dysb $\left.{ }^{1}\right)$, and blos $1^{\text {ex2 }}\left(w^{1118} ; b / o s 1^{\text {ex2 }}\right)$ mutants. Inset, neuronal membrane (HRP; white). B, Quantification of Pldn signal intensity, normalized to HRP intensity, for the indicated genotypes $(n=13-20)$. C , Immunoblot analysis of adult head lysates probed for Pldn in wild type, pld $n^{\Delta 1}, d y s b^{1}, b l o s 1^{e x 2}$. $\boldsymbol{D}$, Quantification of PIdn immunoblot intensity normalized to $\alpha$-tubulin for the genotypes indicated $(n=3)$. $\boldsymbol{E}$, Representative images of Venus-Dysb immunostaining (green) in NMJs of wt+venus-dysb-OE ( $\left.w^{1118} ; \mathrm{OK} 6 /+; U A S-v e n u s-d y s b /+\right)$ and pldn+venus-dysb-OE $\left(w^{1118} ;\right.$ OK6/+;UAS-venus-dysb, pld $n^{\Delta 1 /}$ pld $n^{\Delta 1)}$. The intensity of Venus-Dysb in pldn+venus-dysb-OE $(1.74 \pm 0.11$ a.u., $n=15)$ is significantly increased compared with that of wt+venus-dysb-OE (0.91 \pm 0.09 a.u., $n=9) ; p<0.001$; Student's $t$ test.

PHP is blocked in two BLOC-1 components, we sought to determine whether PHP could be expressed over acute and chronic time scales in pldn mutants.

We applied PhTx to pldn ${ }^{\Delta 1}$ NMJs and measured mEPSP amplitude, EPSP amplitude, and calculated quantal content. Although mEPSP amplitudes were reduced to similar levels in wild-type and pldn mutants due to the acute blockade of postsynaptic glutamate receptors by PhTx (Fig. $5 E$ ), EPSP amplitudes were maintained and PHP was robustly expressed (Fig. 5A,B,F). We then tested whether synaptic homeostasis was expressed normally in pld $n^{\Delta 1}$ mutations when chronically induced due to genetic loss of the postsynaptic glutamate receptor G/uRIIA throughout development, which normally triggers a homeostatic increase in presynaptic release (Petersen et al., 1997). Similar to the acute induction and expression of PHP, PHP is robustly expressed in GluRIIA;pldn mutants (Fig. 5C,D). Thus, pldn is dispensable for both the acute induction and chronic expression of PHP.

\section{pallidin is necessary to maintain and recover the synaptic pool during high activity}

Although we did not observe any major changes in synaptic function under basal conditions in pldn mutants, we asked whether an important function of pldn may be revealed under conditions of synaptic stress. BLOC-1 components have been implicated in endosomal sorting in a variety of tissues, and we considered that during high levels of activity, the importance of pldn at synapses may be revealed. During these conditions, membrane trafficking at synapses must be rapidly and accurately orchestrated to ensure proper endocytosis, sorting, regeneration, and mobilization of synaptic vesicles to maintain the functional vesicle pool and sustain neurotransmission. Indeed, the importance of trafficking and sorting at synaptic endosomes would be highlighted in this condition, and we reasoned that by stressing the synapse through high-intensity stimulation, we may reveal a role for pldn that would not be apparent at rest.

Under conditions of high extracellular calcium, we first stimulated NMJs at $10 \mathrm{~Hz}$ for $10 \mathrm{~min}$ to deplete the synaptic vesicle pool, then measured recovery of the pool for an additional $10 \mathrm{~min}$, taking a test pulse every $5 \mathrm{~s}$. Following an initial rapid depletion typically observed in the initial seconds of stimulation, wild-type synapses largely maintained synaptic vesicle release for the duration of the stimulus, ending at $\sim 80 \%$ of the starting EPSP amplitude and rapidly recovering to above $90 \%$ of prestimulus amplitudes (Fig. 6A). In contrast, this stimulation protocol revealed a more rapid rundown of the synaptic vesicle pool in pldn mutants, ending at $\sim 45 \%$ of the starting EPSP amplitude (Fig. 6A). Further, p/dn mutants failed to fully replenish the depleted synaptic vesicle pool over the course of the next 10 min of recovery following high-frequency stimulation, only recovering to $\sim 60 \%$ of prestimulus amplitudes (Fig. 6A). This level of depletion 
A

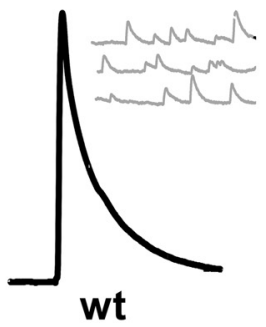

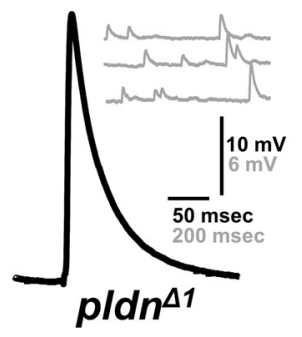

E
B

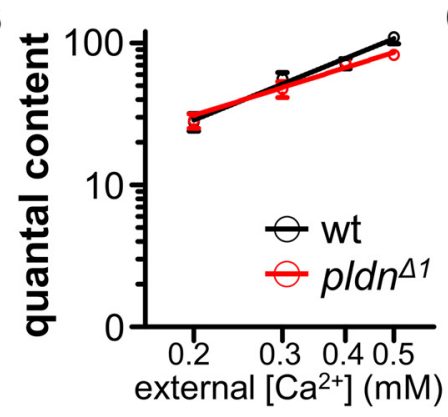

D

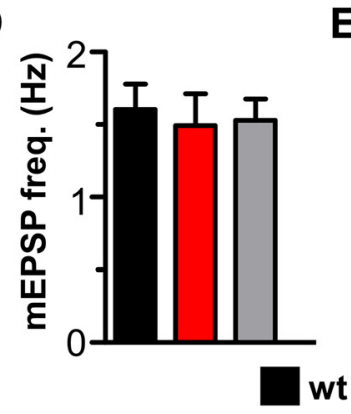

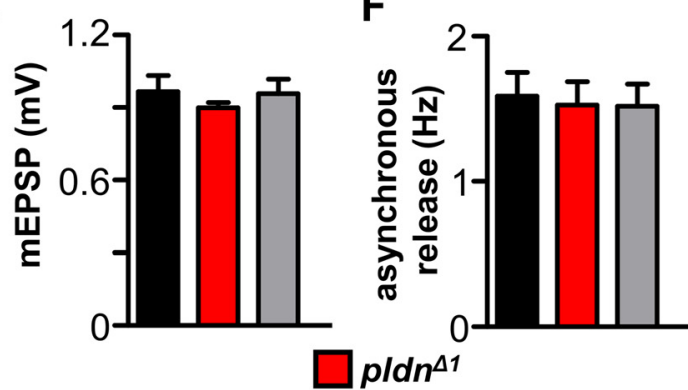

H
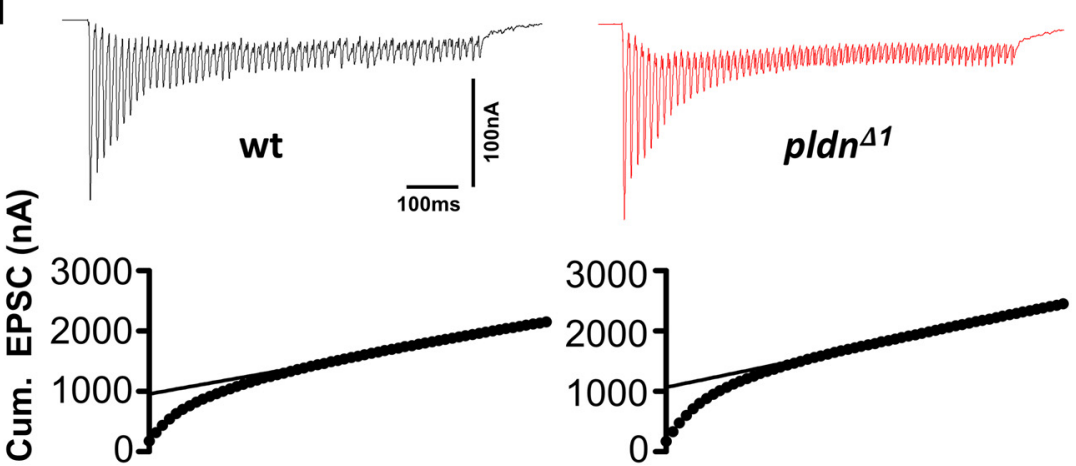

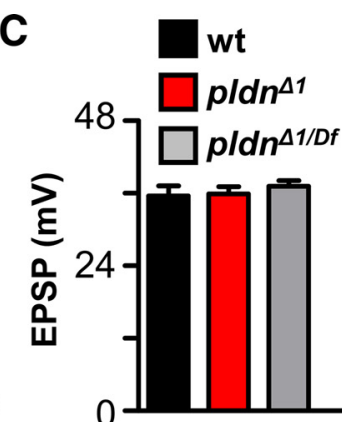

G

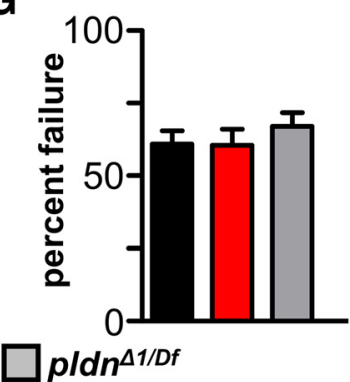

I

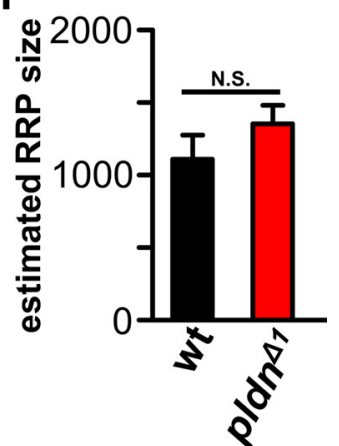

Figure 4. Baseline synaptic transmission is normal in pallidin mutants. A, Representative electrophysiological traces (EPSP and mEPSP traces) from wild-type and $p / d n^{\Delta 1}$ mutant synapses. $\boldsymbol{B}$, Quantal content was determined across a range of extracellular calcium concentrations for wild-type and pld ${ }^{\Delta 1}$ synapses. No significant difference in the slope of the line, indicating the apparent calcium cooperativity of synaptic transmission, was observed. No significant differences were observed in the EPSP amplitude (C), mEPSP frequency $(\boldsymbol{D})$, mEPSP amplitude $(\boldsymbol{E})$, asynchronous release (assayed by determining the mEPSP frequency within the $2 \mathrm{~s}$ immediately after EPSP stimulation) $(\boldsymbol{F})$, or probability of release measured by failure analysis (assayed by \% EPSP failure in $0.1 \mathrm{mM}$ $\left.\mathrm{Ca}^{2+}\right)(\boldsymbol{G})$ in wild-type $(n=10)$, pld $n^{\Delta 1}(n=10)$, and pld $n^{\Delta 1 / D f}(n=10)$ mutant synapses. $\boldsymbol{H}$, Representative EPSC traces (top) and cumulative EPSC amplitudes (bottom) using two electrode voltage clamp evoked by $60-\mathrm{Hz}$ stimulation (60 stimuli) in wild-type and pld $n^{\Delta 1}$ mutant synapses. No significant differences were observed in the estimated readily releasable synaptic vesicle pool (RRP) between wild type $(n=7)$ and $p / d n^{\Delta 1}(n=9)(\eta) . p>0.05$; one-way ANOVA for all parameters.

was significantly reduced when a pldn transgene was expressed in motorneurons in a pldn mutant background, demonstrating that pldn is required presynaptically to maintain the rapidly recycling synaptic vesicle pool.

Given the reduction in PIdn protein levels in both $d y s b^{1}$ and blos $1^{\text {ex }}$ mutants, we considered whether these mutants share a similar deficit in maintaining the rapidly recycling synaptic vesicle pool. Using the same stimulation paradigm, we observed a similar rundown in both $d y s b^{1}$ and blos $1^{\mathrm{ex} 2}$ mutants, as well as a delayed recovery of the depleted synaptic vesicle pool (Fig. 6B). Thus, pldn is necessary for both the sustainment and recovery of the synaptic vesicle pool during and following high levels of activity, a phenotype shared in $d y s b^{1}$ and blos $1^{e x 2}$ mutants, which also exhibits a marked reduction in Pldn expression.

Next, we sought to determine whether the deficit in maintaining the functional vesicle pool during high activity in dysb mutants was due to loss of Pldn itself, or rather whether Dysb may have a direct role in maintaining the recycling vesicle pool. To distinguish between these possibilities, we neuronally overexpressed $p / d n$ in $d y s b$ mutants and overexpressed dysb in pldn mutants. As anticipated by the failure to restore Pldn protein levels at synapses in dysb mutants (Fig. $3 A, B$ ), the rapid rundown of the vesicle pool failed to be rescued in either of these conditions (Fig. 6C). However, we were able to restore the 
A

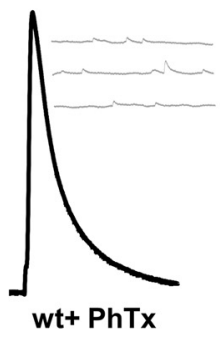

C

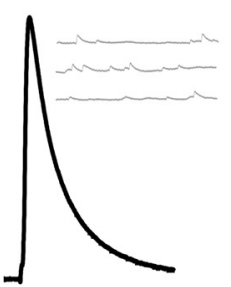

GIURIIA
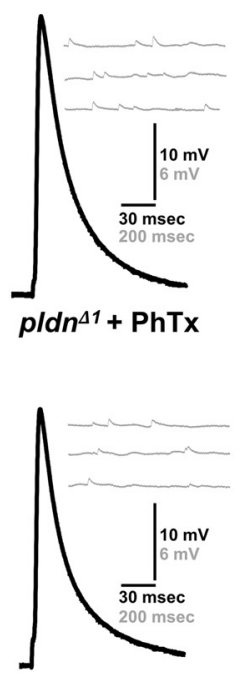

GluRIIA; pldn 41
B $\square_{200}$ EPSP $\square$ content

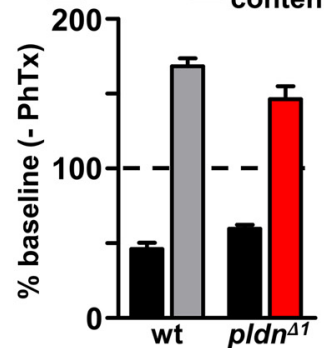

D $\square$ mESSP $\square_{\text {content }}^{\text {quantal }}$

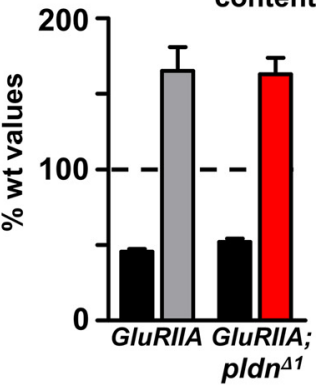

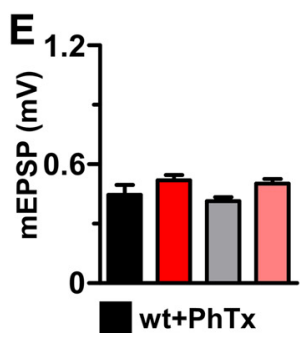
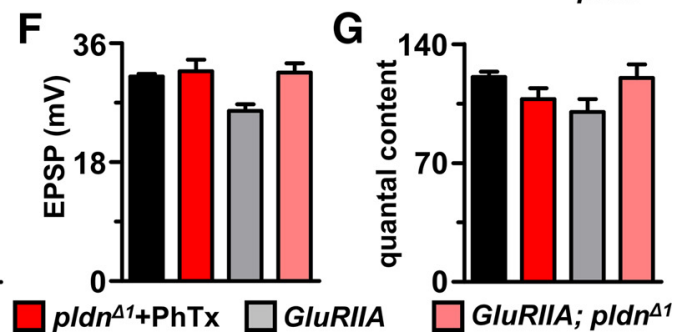

Figure 5. pallidin mutants retain the capacity to express presynaptic homeostatic potentiation. $\boldsymbol{A}$, Representative EPSP and mEPSP traces from wild-type and pld $n^{\Delta 1}$ mutant synapses after PhTx application $(20 \mu \mathrm{M})$. $\boldsymbol{B}$, Normalized mEPSP amplitude and quantal content values of wild-type $(n=10)$ and $p / d n^{\Delta 1}(n=12)$ mutants following PhTx application. Data are normalized to values of each genotype in the absence of PhTx. No deficit in acute presynaptic homeostatic potentiation was observed in pldn $n^{\Delta 1}$ mutants. $\boldsymbol{C}$, Representative EPSP and mEPSP traces from GluRIIA ( $w^{1118} ;$ GluRIIA $\left.{ }^{\text {sp16 }}\right)$ and GluRIIA;pldn ${ }^{\Delta 1}\left(w^{1118} ;\right.$ GluRIIA $^{\text {sp16. }} ;$ pldn $\left.^{\Delta 1}\right)$ mutant synapses. $\boldsymbol{D}$, Normalized mEPSP amplitude and quantal content values of GluRIIA $(n=18)$ and GluRIIA;pldn $n^{\Delta 1}(n=8)$. Data are normalized to wild-type values. No deficit in chronic presynaptic homeostatic potentiation was observed in pld $n^{\Delta 1}$ mutants. $\boldsymbol{E}$, Absolute values of mEPSP amplitude, EPSP amplitude $(\boldsymbol{F})$, and quantal content $(\boldsymbol{G})$ from the normalized data in $B$ and $D$ for the indicated genotypes.

recycling vesicle pool by overexpressing $d y s b$ in $d y s b$ mutants (Fig. 6C). As we have demonstrated that overexpressed Dysb levels were not reduced in pldn mutants (Fig. 3E), this indicates that loss of Pldn itself, and not other BLOC-1 components, likely explains the failure to maintain the recycling vesicle pool in dysb mutants.

Finally, we considered the possibility that pldn may not be necessary for synaptic vesicle recycling per se, but rather for establishing the full size of the starting synaptic vesicle pool. In principle, this pool might be reduced in pldn mutants, given the roles of p/dn and BLOC-1 in vesicle biogenesis (Di Pietro et al., 2006; Delevoye et al., 2016). Indeed, a reduction in the starting vesicle pool could explain the more rapid rundown of the synaptic vesicle pool without necessitating any additional role for Pldn in synaptic vesicle recycling. To determine the size of the entire releasable synaptic vesicle pool, we took advantage of the temperature-sensitive mutation in the Drosophila dynamin gene, shibire (shi). Although synaptic transmission is normal at room temperature in these mu- tants, all synaptic vesicle endocytosis ceases at restrictive temperatures $\left(32^{\circ} \mathrm{C}\right)$ due to a disruption in the ability of Dynamin to drive fission of synaptic vesicles and replenish the vesicle pool (Kuromi and Kidokoro, 1998; Delgado et al., 2000). We measured synaptic transmission at the restrictive temperature in shi mutants alone, as well as in shi;pldn and shi;dysb double mutants (Fig. 6D). In shi mutants alone, full depletion of the entire synaptic vesicle pool was achieved after $\sim 400 \mathrm{~s}$ of stimulation at $15 \mathrm{~Hz}$ in $2 \mathrm{mM}$ extracellular calcium. Transmission ceases because every releasable vesicle is lost without the replenishment of new synaptic vesicles due to this complete block of endocytosis. Importantly, both shi;pldn and shi; dysb mutants also showed similar rates of depletion of the releasable synaptic vesicle pool (Fig. 6D). We calculated the total quanta released in each mutant until full depletion, finding that all genotypes had $\sim 75,000$ total quanta, with no significant differences between the genotypes (Fig. 6E). Thus, pldn is not required for the biogenesis or establishment of a full initial synaptic 
A

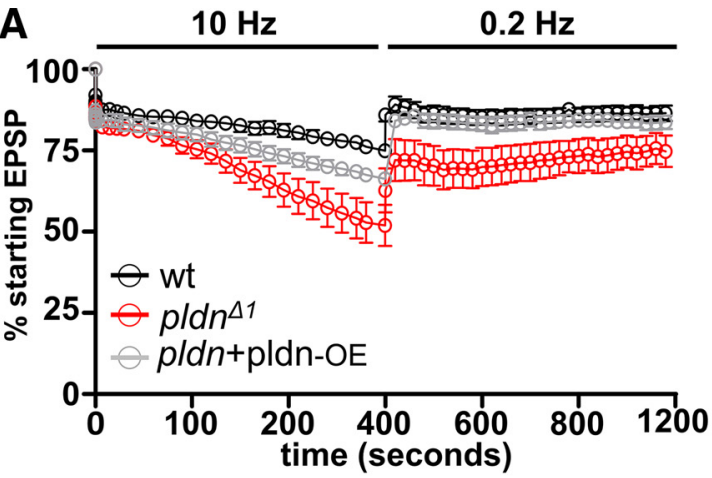

C

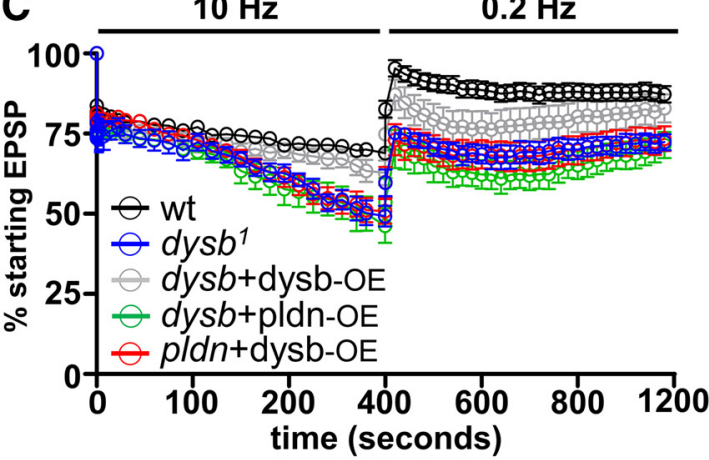

B

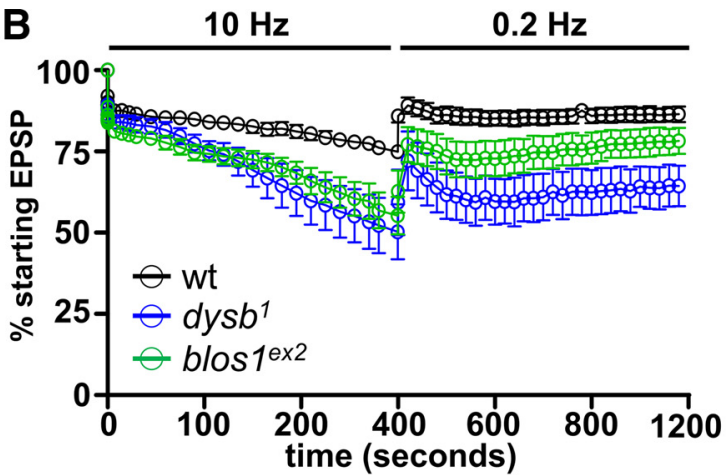

D

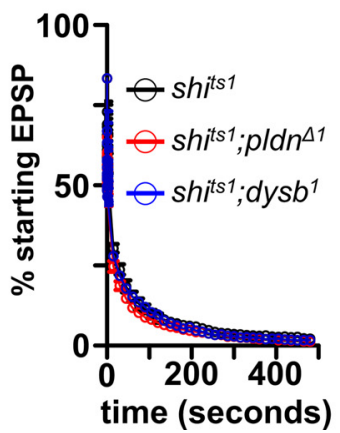

E

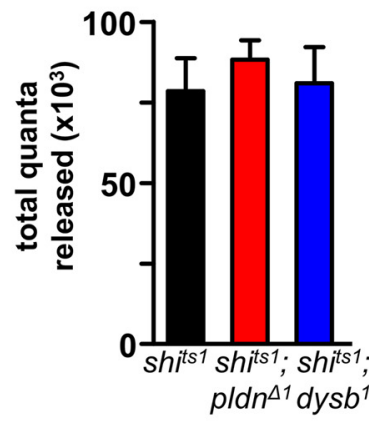

Figure 6. BLOC-1 mutants fail to sustain neurotransmitter release during high-frequency stimulation. $\boldsymbol{A}$, Increased rate of depletion and slowed recovery of the synaptic vesicle pool is observed under high-frequency stimulation in $p / d n^{\Delta 1}$ mutants $(n=15 ; p<0.01$; Student's $t$ test) compared with wild type $(n=11)$. Presynaptic overexpression of pallidin in pld $n^{\Delta 1}$ mutants $(p / d n+$ pldn-OE: $w^{1118} ;$ OK6-Gal4/UAS-pldn; pld $n^{\Delta 1} ; n=12$ ) significantly slows the rate of depletion and increases the rate of recovery. Synapses were stimulated at $10 \mathrm{~Hz}$ in $2 \mathrm{mM}$ extracellular calcium for $10 \mathrm{~min}$, then allowed to recover, taking a test pulse at $0.2 \mathrm{~Hz}$ for the following $10 \mathrm{~min}$. EPSP amplitudes for each time point were binned for $2 \mathrm{~s}$, normalized to prestimulus amplitudes, and plotted as a function of time. $\boldsymbol{B}$, A similar increase in depletion and slowing of recovery is observed in $d y s b^{1}\left(n=9 ; p<0.05\right.$; Student's $t$ test) and blos $1^{\text {ex2 }}$ mutants $\left(n=13 ; p<0.05\right.$; Student's $t$ test). $\boldsymbol{C}$, Both overexpression of $d y s b$ in $p / d n^{\Delta 1}$ mutants (p/dn+dysb-OE: $w^{1118 ; O K 6-G a l 4 /}$ UAS-3xflag-dysb;pldn ${ }^{\Delta 1}, n=12$ ) and overexpression of pldn in dysb ${ }^{1}$ mutants (dysb+pldn-OE: $w^{1118 ; O K 6-G a l 4 / U A S-p l d n-3 x f l a g ; ~}$ $d y s b^{1}, n=12$ ) fail to rescue the increased rundown during high-frequency stimulation. $\boldsymbol{D}$, Determination of the total releasable synaptic vesicle pool. Control $\left(s h i^{t s 1}, n=6\right), p l d n^{\Delta 1}\left(s h i^{t s 1} ; p / d n^{\Delta 1}, n=5\right)$, and $d y s b^{1}\left(s h i^{t s} ;\right.$;ysh $\left.{ }^{1}, n=5\right)$ mutants were stimulated at $10 \mathrm{~Hz}$ in $2 \mathrm{mM}$ calcium at $32^{\circ} \mathrm{C}$ to deplete the total releasable synaptic vesicle pool. EPSP amplitudes at each time point were plotted as a percentage of the starting EPSP amplitude. $\boldsymbol{E}$, No significant difference was observed in the total quanta released between the three genotypes. $p>0.05$; one-way ANOVA.

vesicle pool size, but rather is necessary to rapidly replenish depleted synaptic vesicles during and following high levels of activity.

\section{High synaptic activity depletes FYVE-positive endosomes in pallidin mutants}

A variety of dynamic endosomal structures are known to exist at the presynaptic terminal, where they are involved in modulating diverse aspects of synaptic growth signaling, membrane trafficking and exchange, and synaptic vesicle recycling (Wucherpfennig et al., 2003; Rodal and Littleton, 2008; Uytterhoeven et al., 2011; Saheki and De Camilli, 2012; Kononenko and Haucke, 2015; Deshpande and Rodal, 2016). Given the inability of pldn mutants to sustain the synaptic vesicle pool during highfrequency stimulation, and the associations of BLOC- 1 in controlling endosomal sorting and trafficking, we considered whether endosomal dysfunction may contribute to the failure to sustain the vesicle pool in pldn mutants. In particular, we focused on endosomal structures known to participate in synaptic vesicle recycling. One key endo- some at the synapse that has been characterized in significant detail at the Drosophila NMJ are Rab5-positive early endosomes. These distinct structures are defined by specific labeling with the small GTPase Rab5 (Wucherpfennig et al., 2003; Rodal et al., 2011), and are enriched in the phospholipid phosphatidylinositol-3-phosphate (PI[3]P). PI[3]P specifically binds to the FYVE zinc-finger domain of endosomal factors such as the Rab5 effectors EEA1 and Rabeenosyn-5 (Stenmark et al., 1995;; Lawe et al., 2000; Nielsen et al., 2000; Wucherpfennig et al., 2003). These endosomes serve as sorting stations for synaptic vesicles, directing proteins and membrane to distinct intracellular compartments, including pathways for degradation or the genesis of new synaptic vesicle pools (Wucherpfennig et al., 2003; Uytterhoeven et al., 2011). Ultimately, these key endosomal sorting stations help to maintain the synaptic vesicle pool during high activity, even disappearing when endocytosis from the plasma membrane is blocked due to acute inactivation of shibire (Wucherpfennig et al., 2003). 

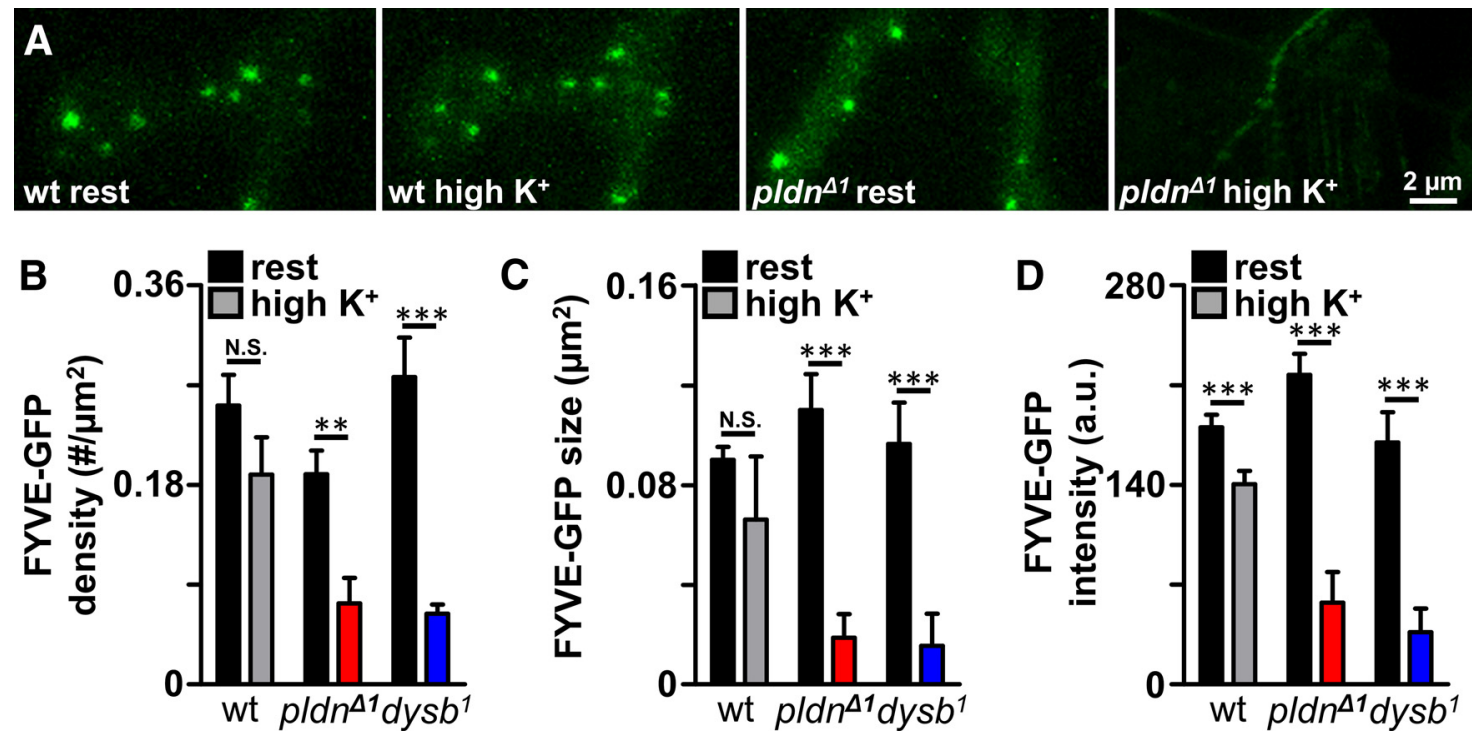

Figure 7. Activity-dependent loss of FYVE-positive synaptic endosomes in pallidin mutants. $\boldsymbol{A}$, GFP-2xFYVE puncta are observed in synapses from control ( $w^{1118}$;OK6-Gal4/UAS-GFP-myc-2xFYVE) and pldn ${ }^{\Delta 1}$ mutants ( ${ }^{1118}$;OK6-Gal4/UAS-GFP-myc-2xFYVE; pld $n^{\Delta 1}$ ) at rest and following a 5-min incubation in $90 \mathrm{mM} \mathrm{KCl}\left(\right.$ high $\mathrm{K}^{+}$). Similar GFP-2xFYVE density and intensity are observed in controls before and after stimulation, whereas $p / d n^{\Delta 1}$ NMJs have reduced GFP-2xFYVE density and intensity following stimulation. Quantification of GFP-2xFYVE density $(\boldsymbol{B})$, size $(\boldsymbol{C})$, and intensity $(\boldsymbol{D})$ in wild-type $(n=13)$, pld $n^{\Delta 1}(n=8)$, and $d y s b^{1}$ mutants $\left(w^{1118} ;\right.$ OK6-Gal4/UAS-GFP-myc-2xFYVE; dysb $\left.{ }^{1} ; n=9\right)$ at rest and following high $\mathrm{K}^{+}$stimulation. $* p<0.05 ; * * p<0.01 ; * * * p<$ 0.001 ; paired Student's $t$ test.

To determine the dynamics and functionality of Rab5positive endosomal structures in the absence of Pldn, we characterized the number and maintenance of these endosomes. First, we expressed GFP-2xFYVE in motor neurons and examined the punctate endosomal structures in synaptic boutons at the NMJ that has been observed by others (Wucherpfennig et al., 2003; Rodal et al., 2011). At rest, FYVE-positive endosomes in pldn mutants showed similar size and density compared with wild type, although pldn mutants displayed a slight reduction in the density of these structures (Fig. $7 A, B$ ). We then subjected the NMJ to stimulation with $90 \mathrm{mM} \mathrm{KCl}$ for $5 \mathrm{~min}$ and found that FYVE-positive endosomes in wild-type terminals maintained their integrity, showing no significant changes in density or size, and a small but significant reduction in fluorescence intensity (Fig. 7). In contrast, GFP-2xFYVE labeled endosomes were greatly reduced following high $\mathrm{K}^{+}$stimulation in pldn mutants, exhibiting large reductions in the density, size, and intensity of GFP2xFYVE puncta (Fig. 7), with a significant fraction disappearing altogether. Similar results were observed in $d y s b$ mutants, consistent with the loss of Pldn and reduced capacity to maintain the recycling vesicle pool in these mutants (Fig. 7B-D). Together, these experiments demonstrate that the activity-dependent maintenance of FYVE-positive early endosomal structures depends on Pldn.

\section{Tubular endosomal structures emerge in pallidin mutant synapses following high activity}

Given the inability to sustain neurotransmission during high-frequency stimulation in pldn mutants, as well as the deficits in maintaining FYVE-positive endosomal struc- tures following activity, we considered whether visualization of synaptic ultrastructure may reveal details about the state of endosomal structures during activity that could not be discerned through confocal imaging alone. At rest, overall synaptic ultrastructure appeared relatively consistent between wild-type, pldn, and dysb genotypes, each showing similar levels of active zones and $\mathrm{T}$ bars, and no significant differences in the size, number, and density of synaptic vesicles at NMJ boutons (Fig. $8 A$ and data not shown). However, cisternal endosomal structures, defined as clear vesicles $>80 \mathrm{~nm}$ in diameter, were increased in both pldn, and dysb mutants at rest (Fig. $8 A, C$ ), suggesting an accumulation of newly formed vesicular structures (Heuser and Reese, 1973; Körber et al., 2012). These are typically transient structures, and cisternal endosomes were observed to accumulate in wild-type synapses following activity (Fig. 8B,D). Interestingly, a similar accumulation of cisternal endosomes at rest were reported in Rab5 mutants (Wucherpfennig et al., 2003), consistent with defects in synaptic vesicle endocytosis and, perhaps, Rab5-dependent endosomal trafficking of recycling synaptic vesicles.

To determine how endosomal structures are altered following high levels of activity and synaptic vesicle recycling, we subjected control, pldn, and dysb genotypes to depolarization in $90 \mathrm{mM} \mathrm{KCl}$ for $5 \mathrm{~min}$, followed by immediate fixation and preparation for electron microscopy (see Materials and Methods). Following stimulation, wildtype NMJs exhibited no significant change in synaptic vesicle density and an increase in cisternal endosomal structures (Fig. 8B-D), consistent with increased rates of endocytosis, as observed in other studies (Akbergenova and Bykhovskaia, 2009). In contrast, analysis of NMJs in 

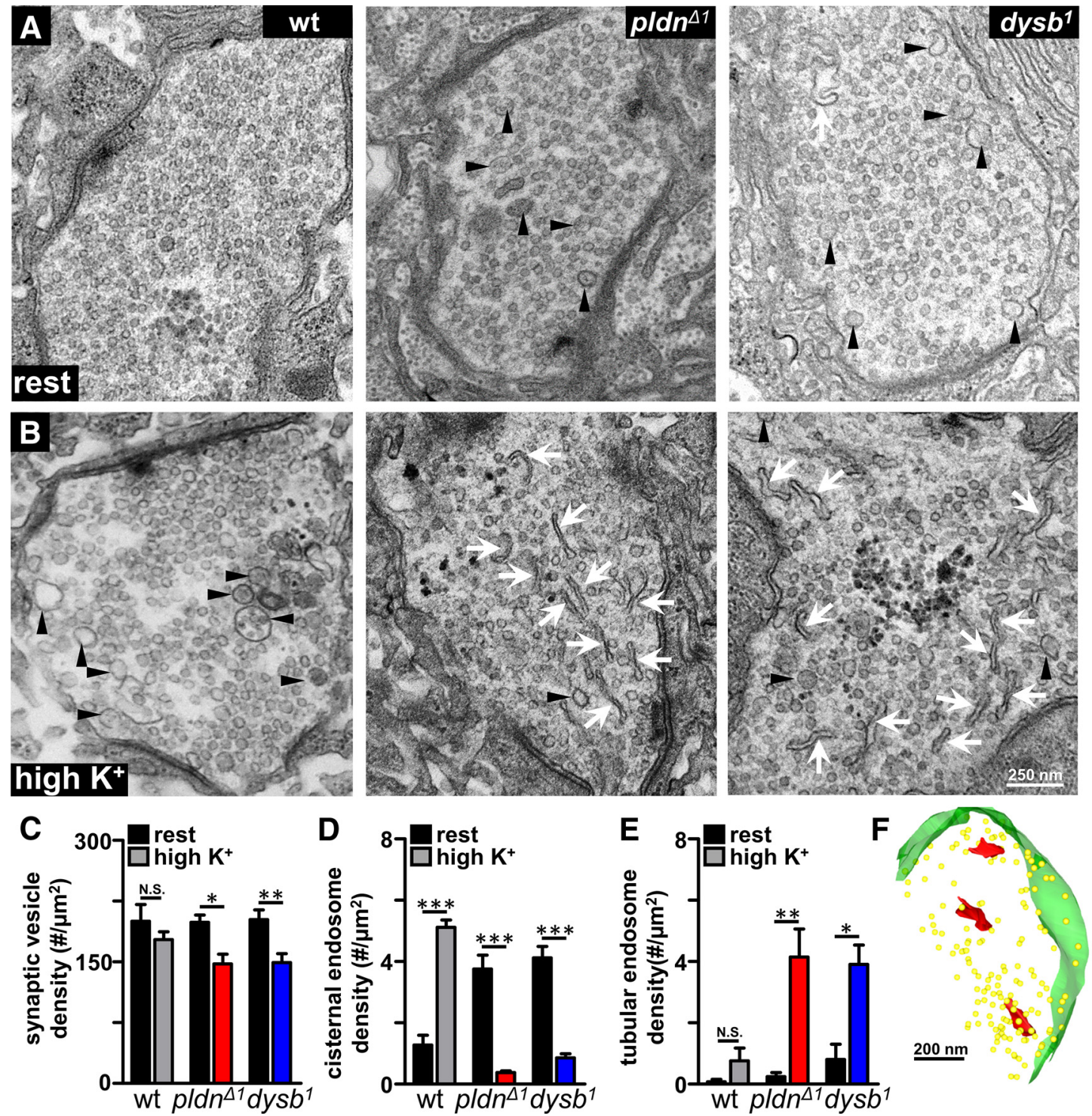

Figure 8. Activity-dependent accumulation of tubular endosomal structures in pallidin mutants. A, Representative electron micrographs of NMJs at rest in wild-type, pldn ${ }^{\Delta 1}$, and $d y s b^{1}$ mutants. $\boldsymbol{B}$, Increased tubular endosomal structures are observed in BLOC-1 mutants following incubation in high $\mathrm{K}^{+}\left(90 \mathrm{mM} \mathrm{K}^{+}, 5 \mathrm{~min}\right)$, while rarely observed in controls. Tubular endosomes (white arrows) and cisternal endosomes (black arrows) are noted. Quantification of the density of synaptic vesicles $(\boldsymbol{C})$, cisternal endosomes $(\boldsymbol{D})$, and tubular endosomes $(E)$ at rest and following high $\mathrm{K}^{+}$stimulation in wild type $\left(n=16\right.$ rest and high $\left.\mathrm{K}^{+}\right)$, pld $n^{\Delta 1}(n=13$ rest and $n=$ 28 high $\mathrm{K}^{+}$), and $d y s b^{1}\left(n=7\right.$ rest and $n=28$ high $\mathrm{K}^{+}$). Note that synaptic vesicle and cisternal endosome densities are reduced, while the tubular endosome density is increased in $p l d n^{\Delta 1}$ and $d y s b^{1}$ mutants following stimulation. $\boldsymbol{F}$, Three-dimensional serial EM reconstruction of tubular endosomal structures (red) near synaptic vesicles (yellow), demonstrating they are not continuous with the plasma membrane (green). $* p<0.05 ; * * p<0.01 ; * * * p<0.001$; Student's $t$ test.

both pldn, and dysb mutants revealed a significant decrease in synaptic vesicle density and cisternal endosomal structures, consistent with reduced recycling rates (Fig. 8B-D). However, the most striking change observed in pldn and dysb synapses following activity was the emergence of tubular endosomal structures (Fig. 8B,E). These structures are rarely observed in wild type, but have been observed at the Drosophila NMJ when Rab5 activity is perturbed (Wucherpfennig et al., 2003). Considering that elevated activity leads to a reduction in FYVEpositive endosomes in pldn and dysb mutants, these tubular structures may be related to a diminishment of
$\mathrm{PI}[3] \mathrm{P}$-enriched synaptic endosomes and a concomitant expansion of the endosomal system.

Finally, we considered the possibility that these tubular endosomal structures were not actually intracellular endosomes but rather were invaginations from the plasma membrane. These invaginations are indicative of an "activity-dependent bulk endocytosis" pathway that can be triggered when other forms of endocytosis are disrupted (Heerssen et al., 2008; Kasprowicz et al., 2008; Verstreken et al., 2009; Wu et al., 2014), and have also been observed in dynamin mutants (Wu et al., 2014). To test whether the tubular endosomes we observed were 
continuous with the plasma membrane, we performed two experiments. First, a bulk endocytosis assay utilizes dextran uptake to reveal synaptic uptake through the activity-dependent bulk endocytic pathway (Clayton and Cousin, 2009b; Uytterhoeven et al., 2011). We performed this assay but did not observe any change in bulk endocytosis levels between wild-type, pldn, and dysb mutants (data not shown). In addition, we performed a 3D serial reconstruction using electron microscopy of the tubular endosomal structures that emerged following high activity in pldn mutants. This reconstruction revealed that these structures are entirely cytosolic and discontinuous with the plasma membrane (Fig. 8F). Together, these results demonstrate that Pldn is necessary during conditions of high synaptic activity to rapidly transition membrane trafficking of synaptic vesicles through key endosomal intermediaries. In the absence of PIdn, tubular endosomal compartments emerge with a concomitant reduction in FYVE-positive early endosomes, leading to a decrease in the rapid and efficient recycling and recovery of the synaptic vesicle pool.

\section{Discussion}

We have generated null mutations in pallidin, a central component of BLOC-1, and characterized synaptic structure and physiology in these mutants. Pldn is present at presynaptic terminals, where it localizes to synaptic microtubules and the cytoskeleton. We find that while pallidin does not have major roles in synaptic growth, structure, or function under basal conditions, pallidin is crucial to maintain the releasable synaptic vesicle pool during conditions of high activity. During these conditions, tubular endosomal structures accumulate with loss of PIdn, while FYVE-positive endosomes are reduced. We also find that the stability of Pldn depends crucially on the BLOC-1 subunits dysbindin and blos 1 and that mutations in these subunits phenocopy pallidin mutants, as expected due to destabilization of the protein. Together, our data demonstrate that although pallidin has no obvious roles in basal synaptic development and function, pallidin has a critical role during adaptive responses to synaptic activity by promoting the efficient trafficking and reformation of synaptic vesicles through FYVE-positive endosomes.

\section{Synaptic functions of Pallidin at the Drosophila NMJ}

We find no major alterations in synaptic development or transmission in pallidin mutants. Further, pallidin mutants are viable and healthy, and although we cannot rule out more subtle phenotypes or differences between species or systems, it is surprising how unperturbed synapses are in pallidin null mutants during basal conditions. In contrast, previous studies have reported moderate changes in synaptic growth, baseline function, and homeostatic plasticity in genetic mutations of other BLOC-1 subunits (Dickman and Davis, 2009; Ghiani et al., 2010; Shao et al., 2011; Wu et al., 2011; Dickman et al., 2012; Zhou et al., 2012; Mullin et al., 2015). For example, baseline synaptic transmission at lowered extracellular calcium is reduced in dysbindin mutants (Dickman and Davis, 2009), yet no such effect is observed in pldn mutants (Fig. 4). In addi- tion, although both dysbindin and snapin are required for acute and chronic forms of synaptic homeostasis in Drosophila (Dickman and Davis, 2009; Dickman et al., 2012), no defects in presynaptic homeostatic plasticity were found in pldn mutants (Fig. 5). Similarly, blos1 mutants were also found to robustly express homeostatic plasticity (Dickman et al., 2012), in contrast to dysbindin and snapin mutants. This suggests that despite being a central part of the BLOC-1 complex, genetic distinctions in synaptic function exist between pallidin and other components in Drosophila. This may be due to partial redundancy and complex gene dosage interactions between BLOC-1 components, as were recently reported (Larimore et al., 2014; Mullin et al., 2015).

Our data suggest that a core function of Pallidin at synapses is to promote the rapid and efficient maintenance of the functional synaptic vesicle pool under conditions of high activity. We found no evidence that pldn controls synaptic vesicle biogenesis, as may have been anticipated for the BLOC-1 complex, because we did not observe any change in the total releasable synaptic vesicle pool (Fig. 6). Instead, pldn is necessary for efficient synaptic vesicle trafficking during conditions of high activity, when at least a subset of synaptic vesicles are guided through endosomal intermediates for sorting, maintenance, and re-formation of critical functional constituents (Wucherpfennig et al., 2003; Jovic et al., 2010; Uytterhoeven et al., 2011; Fernandes et al., 2014). In addition, we observed a striking increase in tubular endosomal structures following activity. These tubular endosomes are rarely if ever observed in wild-type synapses and do not appear at rest in pldn mutants. Interestingly, similar structures have been observed when Rab5 activity is manipulated, when overexpression or dominant negative forms of Rab5 lead to the appearance of similar tubular endosomal structures (Shimizu et al., 2003; Wucherpfennig et al., 2003). These tubular structures are likely the result of an expanded and defective synaptic endosomal system due to abnormal regulation of Rab5 activity; such activities have been reported for other BLOC-1 components (John Peter et al., 2013; Rana et al., 2015). Indeed, there appears to be an intimate relationship between neuronal activity, Pldn, and Rab5 in synaptic vesicle trafficking, as loss of pldn leads to a reduction of FYVE/Rab5-positive endosomes following activity (Fig. 7). More generally, these findings point to a role for pldn and other BLOC-1 components having important and yet distinct functions at synapses during adaptive responses to neuronal stress, such as intense stimulation and homeostatic challenge to neurotransmission.

\section{Pallidin localization, stability, and the BLOC-1 complex}

Pldn is ubiquitously expressed and localizes to cytoskeletal and endosomal structures (Huang et al., 1999; Parast and Otey, 2000; Bang et al., 2001; Falcón-Pérez et al., 2002; Di Pietro et al., 2006). At the Drosophila NMJ, Pldn localized to Z-bands in the postsynaptic muscle (Fig. $1 G)$. These structures are a major cytoskeletal component of muscles that anchors actin filaments to enable muscle 
contraction (Clark et al., 2002; Collin et al., 2012; Granger et al., 2014; Delevoye et al., 2016). It is worthwhile to note that these muscle Z-bands appear disorganized in pldn mutants, suggesting that Pldn is required for the integrity or organization of these structures. In the presynaptic terminal, Pldn exhibits a high degree of colocalization with the neuronal microtubule marker Futsch (Fig. 1D). Given the role of pldn in promoting synaptic vesicle trafficking, this suggests that Pldn may coordinate interactions between synaptic vesicles and the cytoskeleton. Indeed, proper coordination between adaptors and the cytoskeleton is particularly important at synaptic terminals during synaptic vesicle recycling (Ferguson and De Camilli, 2012; Kononenko and Haucke, 2015; Delevoye et al., 2016). Interestingly, two other BLOC-1 subunits, Dysbindin and Snapin, colocalize with synaptic vesicle markers, not cytoskeletal structures (Dickman and Davis, 2009; Dickman et al., 2012). Given the disparate roles in transmission, homeostatic plasticity, and synaptic vesicle endocytosis observed between BLOC-1 subunits, it is tempting to speculate that these distinctions in localization are related to their different functions at synapses.

A variety of studies have noted the apparent unitary nature of the BLOC-1 complex, with significant biochemical evidence that the entire complex associates together as a single entity (Falcón-Pérez et al., 2002; Starcevic and Dell'Angelica, 2004; Setty et al., 2007; Larimore et al., 2014; Delevoye et al., 2016). Further, genetic reductions of some BLOC-1 subunits lead to the biochemical destabilization of other subunits (Falcón-Pérez et al., 2002; Zhang et al., 2002; Ciciotte et al., 2003; Li et al., 2003; Gwynn et al., 2004; Starcevic and Dell'Angelica, 2004; Setty et al., 2007; Feng et al., 2008; Ghiani and Dell'Angelica, 2011; Larimore et al., 2014; Delevoye et al., 2016). For example, Dysbindin and Muted are reduced by up to $60 \%$ and $90 \%$ in brain lysates from pldn mutants in mice (Li et al., 2003). However, complex interactions between BLOC- 1 subunits have been reported (Larimore et al., 2014; Mullin et al., 2015), suggesting simple lossof-function analysis may not always explain important functional properties of the BLOC-1 complex. Further, there is evidence for biochemical subcomplexes of the BLOC-1, in which Pallidin/Blos1/Cappucino and Dysbindin/Snapin/Blos2 exhibit differential association from the entire BLOC-1 complex (Lee et al., 2012). Consistent with these observations, we have found that protein levels of Pldn appear highly dependent on Dysb, where Pallidin is almost completely absent in dysb mutants, and even overexpression of pldn in dysb mutants fails to restore levels Pldn (Fig. $3 A, B$ ). However, this dependence is not reciprocal: dysbindin overexpression in pldn mutants led to no reduction in Dysb levels; if anything, an increase in Dysb was observed (Fig. 3E). Finally, it is loss of Pldn at synapses, and not a function for Dysb itself, which was necessary for rapid endocytosis, since overexpression of $d y s b$ in pldn mutants failed to rescue this phenotype (Fig. 6C).

Interestingly, although Pldn is also reduced in blos $1^{\text {ex2 }}$ mutants, this reduction is not as severe as observed in dysb mutants at presynaptic NMJ terminals. Indeed, this distinction in stability may also be influenced by subcellular expression and/or trafficking of Pldn, as overall levels of Pldn, assessed through immunoblots of whole head lysates, were quantitatively different from levels assessed by immunostaining at the NMJ (Fig.3). Notably, there is some precedence for distinct genetic roles for BLOC-1 components in rodents. The changes in coat color observed in pallidin, dysbindin, and other BLOC-1 mutants are not exactly the same and have not been reported in snapin mutants (Tian et al., 2005), nor have the neurodegenerative defects reported in snapin mutants (Cai et al., 2010; Tian et al., 2005) been observed for other BLOC-1 mutants. Ultimately, BLOC-1 components at synapses appear to be involved in membrane trafficking, with complex interrelationships between individual components in regulating protein stability and functions in adaptive responses to synaptic stress.

\section{References}

Akbergenova Y, Bykhovskaia M (2009) Enhancement of the endosomal endocytic pathway increases quantal size. Mol Cell Neurosci 40:199-206. CrossRef

Bang ML, Mudry RE, McElhinny AS, Trombitás K, Geach AJ, Yamasaki R, Sorimachi H, Granzier H, Gregorio CC, Labeit S (2001) Myopalladin, a novel 145-kilodalton sarcomeric protein with multiple roles in Z-disc and I-band protein assemblies. J Cell Biol 153:413-427. CrossRef

Brown HM, Van Epps HA, Goncharov A, Grant BD, Jin Y (2009) The JIP3 scaffold protein UNC-16 regulates RAB-5 dependent membrane trafficking at C. elegans synapses. Dev Neurobiol 69:174190. CrossRef Medline

Cai Q, Lu L, Tian JH, Zhu YB, Qiao H, Sheng ZH (2010) Snapinregulated late endosomal transport is critical for efficient autophagy-lysosomal function in neurons. Neuron 68:73-86. CrossRef

Cheli VT, Daniels RW, Godoy R, Hoyle DJ, Kandachar V, Starcevic M, Martinez-Agosto JA, Poole S, DiAntonio A, Lloyd VK, Chang HC, Krantz DE, Dell'Angelica EC (2010) Genetic modifiers of abnormal organelle biogenesis in a Drosophila model of BLOC-1 deficiency. Hum Mol Genet 19:861-878. CrossRef

Chen XW, Feng YQ, Hao CJ, Guo XL, He X, Zhou ZY, Guo N, Huang HP, Xiong W, Zheng H, et al. (2008) DTNBP1, a schizophrenia susceptibility gene, affects kinetics of transmitter release. J Cell Biol 181:791-801. CrossRef

Ciciotte SL, Gwynn B, Moriyama K, Huizing M, Gahl WA, Bonifacino JS, Peters LL (2003) Cappuccino, a mouse model of HermanskyPudlak syndrome, encodes a novel protein that is part of the pallidin-muted complex (BLOC-1). Blood 101:4402-4407. CrossRef

Clark KA, McElhinny AS, Beckerle MC, Gregorio CC (2002) Striated muscle cytoarchitecture: an intricate web of form and function. Annu Rev Cell Dev Biol 18:637-706. CrossRef Medline

Clayton EL, Cousin MA (2009a) The molecular physiology of activitydependent bulk endocytosis of synaptic vesicles. J Neurochem 111:901-914. CrossRef Medline

Clayton EL, Cousin MA (2009b) Quantitative monitoring of activitydependent bulk endocytosis of synaptic vesicle membrane by fluorescent dextran imaging. J Neurosci Methods 185:76-81.

Collin GB, Marshall JD, King BL, Milan G, Maffei P, Jagger DJ, Naggert JK (2012) The Alström syndrome protein, ALMS1, interacts with alpha-actinin and components of the endosome recycling pathway. PLoS One 7:e37925. CrossRef

Davis GW, Müller M (2015) Homeostatic control of presynaptic neurotransmitter release. Ann Rev Physiol 77:251-270. CrossRef Medline

de Hoop MJ, Huber LA, Stenmark H, Williamson E, Zerial M, Parton RG, Dotti CG (1994) The involvement of the small GTP-binding 
protein Rab5a in neuronal endocytosis. Neuron 13:11-22. CrossRef

Delevoye C, Heiligenstein X, Ripoll L, Gilles-Marsens F, Dennis MK, Linares RA, Derman L, Gokhale A, Morel E, Faundez V, Marks MS, Raposo G (2016) BLOC-1 brings together the actin and microtubule cytoskeletons to generate recycling endosomes. Curr Biol 26:1-13. CrossRef

Delgado R, Maureira C, Oliva C, Kidokoro Y, Labarca P (2000) Size of vesicle pools, rates of mobilization, and recycling at neuromuscular synapses of a Drosophila mutant, shibire. Neuron 28:941953. CrossRef

Deshpande M, Rodal AA (2016) The crossroads of synaptic growth signaling, membrane traffic and neurological disease: insights from Drosophila. Traffic 17:87-101. CrossRef

Dickman DK, Davis GW (2009) The schizophrenia susceptibility gene dysbindin controls synaptic homeostasis. Science 326:11271130. CrossRef

Dickman DK, Tong A, Davis GW (2012) Snapin is critical for presynaptic homeostatic plasticity. J Neurosci 32:8716-8724. CrossRef Medline

Di Pietro SM, Falcon-Perez JM, Tenza D, Setty SR, Marks MS, Raposo G, Dell'Angelica EC (2006) BLOC-1 interacts with BLOC-2 and the AP-3 complex to facilitate protein trafficking on endosomes. Mol Biol Cell 17:4027-4038. CrossRef

Falcón-Pérez JM, Starcevic M, Gautam R, Dell'Angelica EC (2002) BLOC-1, a novel complex containing the pallidin and muted proteins involved in the biogenesis of melanosomes and plateletdense granules. J Biol Chem 277:28191-28199. CrossRef

Feng YQ, Zhou ZY, He X, Wang H, Guo XL, Hao CJ, Guo Y, Zhen XC, Li W (2008) Dysbindin deficiency in sandy mice causes reduction of snapin and displays behaviors related to schizophrenia. Schizophr Res 106:218-228. CrossRef

Ferguson SM, De Camilli P (2012) Dynamin, a membraneremodelling GTPase. Nat Rev Mol Cell Biol 13:75-88. CrossRef Medline

Fernandes AC, Uytterhoeven V, Kuenen S, Wang YC, Slabbaert JR, Swerts J, Kasprowicz J, Aerts S, Verstreken P (2014) Reduced synaptic vesicle protein degradation at lysosomes curbs TBC1D24/sky-induced neurodegeneration. J Cell Biol 207:453462. CrossRef

Frank CA (2014) Homeostatic plasticity at the Drosophila neuromuscular junction. Neuropharmacology 78:63-74. CrossRef

Frank CA, Kennedy MJ, Goold CP, Marek KW, Davis GW (2006) Mechanisms underlying the rapid induction and sustained expression of synaptic homeostasis. Neuron 52:663-677. CrossRef

Frank CA, Wang X, Collins CA, Rodal AA, Yuan Q, Verstreken P, Dickman DK (2013) New approaches for studying synaptic development, function, and plasticity using Drosophila as a model system. J Neurosci 33:17560-17568. CrossRef

Ghiani CA, Dell'Angelica EC (2011) Dysbindin-containing complexes and their proposed functions in brain: from zero to (too) many in a decade. ASN Neuro 3. CrossRef

Ghiani CA, Starcevic M, Rodriguez-Fernandez IA, Nazarian R, Cheli VT, Chan LN, Malvar JS, de Vellis J, Sabatti C, Dell'Angelica EC (2010) The dysbindin-containing complex (BLOC-1) in brain: developmental regulation, interaction with SNARE proteins and role in neurite outgrowth. Mol Psychiatry 15:204-215. CrossRef

Granger E, McNee G, Allan V, Woodman P (2014) The role of the cytoskeleton and molecular motors in endosomal dynamics. Semin Cell Dev Biol 31:20-29. CrossRef

Gwynn B, Martina JA, Bonifacino JS, Sviderskaya EV, Lamoreux ML, Bennett DC, Moriyama K, Huizing M, Helip-Wooley A, Gahl WA, Webb LS, Lambert AJ, Peters LL (2004) Reduced pigmentation (rp), a mouse model of Hermansky-Pudlak syndrome, encodes a novel component of the BLOC-1 complex. Blood 104:3181-3189. CrossRef

Han C, Jan LY, Jan YN (2011) Enhancer-driven membrane markers for analysis of nonautonomous mechanisms reveal neuron-glia interactions in Drosophila. Proc Natl Acad Sci USA 108:96739678. CrossRef
Heerssen H, Fetter RD, Davis GW (2008) Clathrin dependence of synaptic-vesicle formation at the Drosophila neuromuscular junction. Curr Biol 18:401-409. CrossRef

Heuser JE, Reese TS (1973) Evidence for recycling of synaptic vesicle membrane during transmitter release at the frog neuromuscular junction. J Cell Biol 57:315-344. CrossRef

Hoopmann P, Punge A, Barysch SV, Westphal V, Bückers J, Opazo F, Bethani I, Lauterbach MA, Hell SW, Rizzoli SO (2010) Endosomal sorting of readily releasable synaptic vesicles. Proc Natl Acad Sci USA 107:19055-19060. CrossRef Medline

Huang L, Kuo YM, Gitschier J (1999) The pallid gene encodes a novel, syntaxin 13-interacting protein involved in platelet storage pool deficiency. Nat Genet 23:329-332. CrossRef Medline

Hummel T, Krukkert K, Roos J, Davis G, Klämbt C (2000) Drosophila Futsch/22C10 is a MAP1B-like protein required for dendritic and axonal development. Neuron 26:357-370. Medline

John Peter AT, Lachmann J, Rana M, Bunge M, Cabrera M, Ungermann C (2013) The BLOC-1 complex promotes endosomal maturation by recruiting the Rab5 GTPase-activating protein Msb3. J Cell Biol 201:97-111. CrossRef

Jovic M, Sharma M, Rahajeng J, Caplan S (2010) The early endosome: a busy sorting station for proteins at the crossroads. Histol Histopathol 25:99-112. Medline

Kasprowicz J, Kuenen S, Miskiewicz K, Habets RL, Smitz L, Verstreken $P$ (2008) Inactivation of clathrin heavy chain inhibits synaptic recycling but allows bulk membrane uptake. J Cell Biol 182:1007-1016. CrossRef

Kaufmann N, DeProto J, Ranjan R, Wan H, Van Vactor D (2002) Drosophila liprin-alpha and the receptor phosphatase Dlar control synapse morphogenesis. Neuron 34:27-38. CrossRef

Koh YH, Popova E, Thomas U, Griffith LC, Budnik V (1999) Regulation of DLG localization at synapses by CaMKII-dependent phosphorylation. Cell 98:353-363. Medline

Kononenko NL, Haucke V (2015) Molecular mechanisms of presynaptic membrane retrieval and synaptic vesicle reformation. Neuron 85:484-496. CrossRef Medline

Körber C, Horstmann H, Sätzler K, Kuner T (2012) Endocytic structures and synaptic vesicle recycling at a central synapse in awake rats. Traffic 13:1601-1611. CrossRef Medline

Kremer JR, Mastronarde DN, McIntosh JR (1996) Computer visualization of three-dimensional image data using IMOD. J Struct Biol 116:71-76. CrossRef Medline

Kuromi H, Kidokoro Y (1998) Two distinct pools of synaptic vesicles in single presynaptic boutons in a temperature-sensitive Drosophila mutant, shibire. Neuron 20:917-925. CrossRef

Larimore J, Zlatic SA, Gokhale A, Tornieri K, Singleton KS, Mullin AP, Tang J, Talbot K, Faundez V (2014) Mutations in the BLOC-1 subunits dysbindin and muted generate divergent and dosagedependent phenotypes. J Biol Chem 289:14291-14300. CrossRef

Lawe DC, Patki V, Heller-Harrison R, Lambright D, Corvera S (2000) The FYVE domain of early endosome antigen 1 is required for both phosphatidylinositol 3-phosphate and Rab5 binding. Critical role of this dual interaction for endosomal localization. $J$ Biol Chem 275:3699-3705. CrossRef

Lee HH, Nemecek D, Schindler C, Smith WJ, Ghirlando R, Steven AC, Bonifacino JS, Hurley JH (2012) Assembly and architecture of biogenesis of lysosome-related organelles complex-1 (BLOC-1). J Biol Chem 287:5882-5890. CrossRef

Li W, Zhang Q, Oiso N, Novak EK, Gautam R, O'Brien EP, Tinsley CL, Blake DJ, Spritz RA, Copeland NG, Jenkins NA, Amato D, Roe BA, Starcevic M, Dell'Angelica EC, Elliott RW, Mishra V, Kingsmore SF, Paylor RE, Swank RT (2003) Hermansky-Pudlak syndrome type 7 (HPS-7) results from mutant dysbindin, a member of the biogenesis of lysosome-related organelles complex 1 (BLOC-1). Nat Genet 35:84-89. CrossRef

Martin AR (1955) A further study of the statistical composition on the end-plate potential. J Physiol 130:114-122. Medline

McMahon HT, Boucrot E (2011) Molecular mechanism and physiological functions of clathrin-mediated endocytosis. Nat Rev Mol Cell Biol 12:517-533. CrossRef Medline 
Morris DW, Murphy K, Kenny N, Purcell SM, McGhee KA, Schwaiger S, Nangle JM, Donohoe G, Clarke S, Scully P, et al. (2008) Dysbindin (DTNBP1) and the biogenesis of lysosome-related organelles complex 1 (BLOC-1): main and epistatic gene effects are potential contributors to schizophrenia susceptibility. Biol Psychiatry 63:24-31. CrossRef

Muller M, Liu KS, Sigrist SJ, Davis GW (2012) RIM controls homeostatic plasticity through modulation of the readily-releasable vesicle pool. J Neurosci 32:16574-16585. CrossRef

Mullin AP, Sadanandappa MK, Ma W, Dickman DK, VijayRaghavan K, Ramaswami M, Sanyal S, Faundez V (2015) Gene dosage in the dysbindin schizophrenia susceptibility network differentially affect synaptic function and plasticity. J Neurosci 35:325-338. CrossRef

Murthy VN, De Camilli P (2003) Cell biology of the presynaptic terminal. Annu Rev Neurosci 26:701-728. CrossRef Medline

Nielsen E, Christoforidis S, Uttenweiler-Joseph S, Miaczynska M, Dewitte F, Wilm M, Hoflack B, Zerial M (2000) Rabenosyn-5, a novel Rab5 effector, is complexed with hVPS45 and recruited to endosomes through a FYVE finger domain. J Cell Biol 151:601612. CrossRef

Numakawa T, Yagasaki Y, Ishimoto T, Okada T, Suzuki T, Iwata N, Ozaki N, Taguchi T, Tatsumi M, Kamijima K, Straub RE, Weinberger DR, Kunugi H, Hashimoto R (2004) Evidence of novel neuronal functions of dysbindin, a susceptibility gene for schizophrenia. Hum Mol Genet 13:2699-2708. CrossRef

Pan PY, Tian JH, Sheng ZH (2009) Snapin facilitates the synchronization of synaptic vesicle fusion. Neuron 61:412-424. CrossRef Medline

Parast MM, Otey CA (2000) Characterization of palladin, a novel protein localized to stress fibers and cell adhesions. J Cell Biol 150:643-656. Medline

Parks AL, Cook KR, Belvin M, Dompe NA, Fawcett R, Huppert K, Tan LR, Winter CG, Bogart KP, Deal JE, Deal-Herr ME, Grant D, Marcinko M, Miyazaki WY, Robertson S, Shaw KJ, Tabios M, Vysotskaia V, Zhao L, Andrade RS, et al. (2004) Systematic generation of high-resolution deletion coverage of the Drosophila melanogaster genome. Nat Genet 36:288-292. CrossRef

Petersen SA, Fetter RD, Noordermeer JN, Goodman CS, DiAntonio A (1997) Genetic analysis of glutamate receptors in Drosophila reveals a retrograde signal regulating presynaptic transmitter release. Neuron 19:1237-1248. CrossRef

Rana M, Lachmann J, Ungermann C (2015) Identification of a Rab GTPase-activating protein cascade that controls recycling of the Rab5 GTPase Vps21 from the vacuole. Mol Biol Cell 26:25352549. CrossRef Medline

Rizzoli SO (2014) Synaptic vesicle recycling: steps and principles. EMBO J 33:788-822. CrossRef Medline

Rodal AA, Blunk AD, Akbergenova Y, Jorquera RA, Buhl LK, Littleton JT (2011) A presynaptic endosomal trafficking pathway controls synaptic growth signaling. J Cell Biol 193:201-217. CrossRef

Rodal AA, Littleton JT (2008) Synaptic endocytosis: illuminating the role of clathrin assembly. Curr Biol 18:R259-R261. CrossRef Medline

Ryder E, Ashburner M, Bautista-Llacer R, Drummond J, Webster J, Johnson G, Morley T, Chan YS, Blows F, Coulson D, Reuter G, Baisch H, Apelt C, Kauk A, Rudolph T, Kube M, Klimm M, Nickel C, Szidonya J, Maróy P, et al. (2007) The DrosDel deletion collection: a Drosophila genomewide chromosomal deficiency resource. Genetics 177:615-629. CrossRef

Ryder PV, Faundez V (2009) Schizophrenia: the "BLOC" may be in the endosomes. Sci Signal 2:pe66. CrossRef Medline

Saheki Y, De Camilli P (2012) Synaptic vesicle endocytosis. Cold Spring Harb Perspect Biol 4:a005645. CrossRef Medline

Salem N, Faúndez V, Horng JT, Kelly RB (1998) A v-SNARE participates in synaptic vesicle formation mediated by the AP3 adaptor complex. Nat Neurosci 1:551-556. CrossRef

Setty SR, Tenza D, Truschel ST, Chou E, Sviderskaya EV, Theos AC, Lamoreux ML, Di Pietro SM, Starcevic M, Bennett DC, et al. (2007) BLOC-1 is required for cargo-specific sorting from vacuolar early endosomes toward lysosome-related organelles. Mol Biol Cell 18:768-780. CrossRef

Shao L, Shuai Y, Wang J, Feng S, Lu B, Li Z, Zhao Y, Wang L, Zhong $Y$ (2011) Schizophrenia susceptibility gene dysbindin regulates glutamatergic and dopaminergic functions via distinctive mechanisms in Drosophila. Proc Natl Acad Sci USA 108:18831-18836. CrossRef

Shimizu H, Kawamura S, Ozaki K (2003) An essential role of Rab5 in uniformity of synaptic vesicle size. J Cell Sci 116:3583-3590. CrossRef Medline

Smith SM, Renden R, von Gersdorff H (2008) Synaptic vesicle endocytosis: fast and slow modes of membrane retrieval. Trends Neurosci 31:559-568. CrossRef Medline

Soykan T, Maritzen T, Haucke V (2016) Modes and mechanisms of synaptic vesicle recycling. Curr Opin Neurobiol 39:17-23. CrossRef Medline

Starcevic M, Dell'Angelica EC (2004) Identification of snapin and three novel proteins (BLOS1, BLOS2, and BLOS3/reduced pigmentation) as subunits of biogenesis of lysosome-related organelles complex-1 (BLOC-1). J Biol Chem 279:28393-28401. CrossRef

Stenmark H, Vitale G, Ullrich O, Zerial M (1995) Rabaptin-5 is a direct effector of the small GTPase Rab5 in endocytic membrane fusion. Cell 83:423-432. Medline

Straub RE, Jiang Y, MacLean CJ, Ma Y, Webb BT, Myakishev MV, Harris-Kerr C, Wormley B, Sadek H, Kadambi B, Cesare AJ, Gibberman A, Wang X, O'Neill FA, Walsh D, Kendler KS (2002) Genetic variation in the 6p22.3 gene DTNBP1, the human ortholog of the mouse dysbindin gene, is associated with schizophrenia. Am J Hum Genet 71:337-348. CrossRef

Sudhof TC (2004) The synaptic vesicle cycle. Annu Rev Neurosci 27:509-547. CrossRef Medline

Tang TT, Yang F, Chen BS, Lu Y, Ji Y, Roche KW, Lu B (2009) Dysbindin regulates hippocampal LTP by controlling NMDA receptor surface expression. Proc Natl Acad Sci USA 106:21395-21400. CrossRef Medline

Thibault ST, Singer MA, Miyazaki WY, Milash B, Dompe NA, Singh CM, Buchholz R, Demsky M, Fawcett R, Francis-Lang HL, Ryner L, Cheung LM, Chong A, Erickson C, Fisher WW, Greer K, Hartouni SR, Howie E, Jakkula L, Joo D, et al. (2004) A complementary transposon tool kit for Drosophila melanogaster using $\mathrm{P}$ and piggyBac. Nat Genet 36:283-287. CrossRef

Tian JH, Wu ZX, Unzicker M, Lu L, Cai Q, Li C, Schirra C, Matti U, Stevens D, Deng C, Rettig J, Sheng ZH (2005) The role of Snapin in neurosecretion: snapin knock-out mice exhibit impaired calcium-dependent exocytosis of large dense-core vesicles in chromaffin cells. J Neurosci 25:10546-10555. CrossRef

Uytterhoeven V, Kuenen S, Kasprowicz J, Miskiewicz K, Verstreken P (2011) Loss of skywalker reveals synaptic endosomes as sorting stations for synaptic vesicle proteins. Cell 145:117-132. CrossRef

Venken KJ, He Y, Hoskins RA, Bellen HJ (2006) P[acman]: a BAC transgenic platform for targeted insertion of large DNA fragments in D. melanogaster. Science 314:1747-1751. CrossRef Medline

Verstreken P, Ohyama T, Haueter C, Habets RL, Lin YQ, Swan LE, Ly CV, Venken KJ, De Camilli P, Bellen HJ (2009) Tweek, an evolutionarily conserved protein, is required for synaptic vesicle recycling. Neuron 63:203-215. CrossRef Medline

Voglmaier SM, Kam K, Yang H, Fortin DL, Hua Z, Nicoll RA, Edwards $\mathrm{RH}$ (2006) Distinct endocytic pathways control the rate and extent of synaptic vesicle protein recycling. Neuron 51:71-84. CrossRef

Wei ML (2006) Hermansky-Pudlak syndrome: a disease of protein trafficking and organelle function. Pigment Cell Res 19:19-42. CrossRef Medline

Wu CS, Lin JT, Chien CL, Chang WC, Lai HL, Chang CP, Chern Y (2011) Type VI adenylyl cyclase regulates neurite extension by binding to Snapin and Snap25. Mol Cell Biol 31:4874-4886. CrossRef 
Wu Y, O'Toole ET, Girard M, Ritter B, Messa M, Liu X, McPherson PS, Ferguson SM, De Camilli P (2014) A dynamin 1-, dynamin 3and clathrin-independent pathway of synaptic vesicle recycling mediated by bulk endocytosis. Elife 3:e01621. CrossRef

Wucherpfennig T, Wilsch-Bräuninger M, González-Gaitán M (2003) Role of Drosophila Rab5 during endosomal trafficking at the synapse and evoked neurotransmitter release. J Cell Biol 161:609624. CrossRef
Zhang Q, Li W, Novak EK, Karim A, Mishra VS, Kingsmore SF, Roe BA, Suzuki T, Swank RT (2002) The gene for the muted (mu) mouse, a model for Hermansky-Pudlak syndrome, defines a novel protein which regulates vesicle trafficking. Hum Mol Genet 11:697-706. CrossRef

Zhou B, Cai Q, Xie Y, Sheng ZH (2012) Snapin recruits dynein to BDNF-TrkB signaling endosomes for retrograde axonal transport and is essential for dendrite growth of cortical neurons. Cell Rep 2:42-51. CrossRef 